\title{
PROPUESTA DE RECONSTRUCCIÓN GRÁFICA DE LAS IGLESIAS MEDIEVALES DE SANTO DOMINGO DE SILOS. SÍNTESIS DE LA HISTORIOGRAFÍA RECIENTE
}

\author{
RODRIGO ANTOLÍN MINAYA \\ Universidad Nacional de Educación a Distancia
}

Fecha de recepción: 08/04/2021

Fecha de aceptación: 24/07/2021

\begin{abstract}
Resumen
Entre los siglos X y XIII la desaparecida iglesia de Santo Domingo de Silos se vio sometida a continuas reformas y ampliaciones que se solapaban unas a otras. El presente trabajo plantea propuestas de reconstrucción gráfica sobre la imagen aproximada que pudo tener cada una de aquellas intervenciones, recurriendo para ello al estudio de las diferentes hipótesis que han planteado los historiadores durante los últimos años. El trabajo, por tanto, es un recorrido por la historiografía reciente, de la que tomaremos las propuestas que consideramos más adecuadas a cada caso, las cuales intentaremos justificar a partir de nuestras propias observaciones.
\end{abstract}

\section{Palabras clave}

Planimetría; románico; prerrománico; arqueología; planta.

\section{PROPOSAL FOR THE GRAPHIC RECONSTRUCTION OF THE MEDIEVAL CHURCHES OF SANTO DOMINGO DE SILOS. SYNTHESIS OF RECENT HISTORIOGRAPHY}

\begin{abstract}
Between the X and XIII centuries the disappeared church of Santo Domingo de Silos was submitted to continuous reforms and extensions that overlapped each other. The present work tries to raise proposals of graphical reconstruction on the approximate image that could have each one of those interventions, in order to do so, it resorted to the study of the different hypotheses that historians have been putting over the last few years. The work, therefore, is a historiographical journey from which we will take the proposals we consider most appropriate in each case, which we will try to justify on the basis of our own observations.
\end{abstract}

\section{Keywords}

Planimetry; romanesque; pre-Romanesque; archaeology; plan. 
En 1751 comenzaba en Santo Domingo de Silos la construcción de una nueva iglesia que supuso la desaparición de su antiguo templo románico, del que solo sobrevivió el brazo meridional del transepto por haber sido reutilizado antes como acceso a la capilla barroca del santo ${ }^{1}$. Aquel edificio medieval no fue el resultado de un proyecto unitario, sino que su forma se fue definiendo por sucesivas ampliaciones que, entre los siglos X y XIII, se solaparon unas a otras. Este complejo proceso constructivo ha generado un importante número de propuestas de reconstrucción que, con una interpretación diferente de las fuentes conservadas, han intentado dilucidar la forma que tuvo el edificio en cada momento, dando lugar a variadas hipótesis sobre la evolución y la estructura de la antigua iglesia ${ }^{2}$.

Para plantear esos modelos de reconstrucción los historiadores han manejado distintas fuentes, entre las que destacan los restos arqueológicos conservados bajo el suelo del actual edificio y aún visibles en su cripta ${ }^{3}$ (fig.1), dos planos anteriores a la destrucción de la iglesia atribuidos a Manuel Machuca y Rodrigo Echevarría ${ }^{4}$ (fig.2) y, por último, algunas aportaciones documentales sobre el monasterio, especialmente las de Grimaldo en torno a $1090^{5}$, las de Jerónimo Nebreda cerca de $1578^{6}$ y las del abad Baltasar Díaz en paralelo

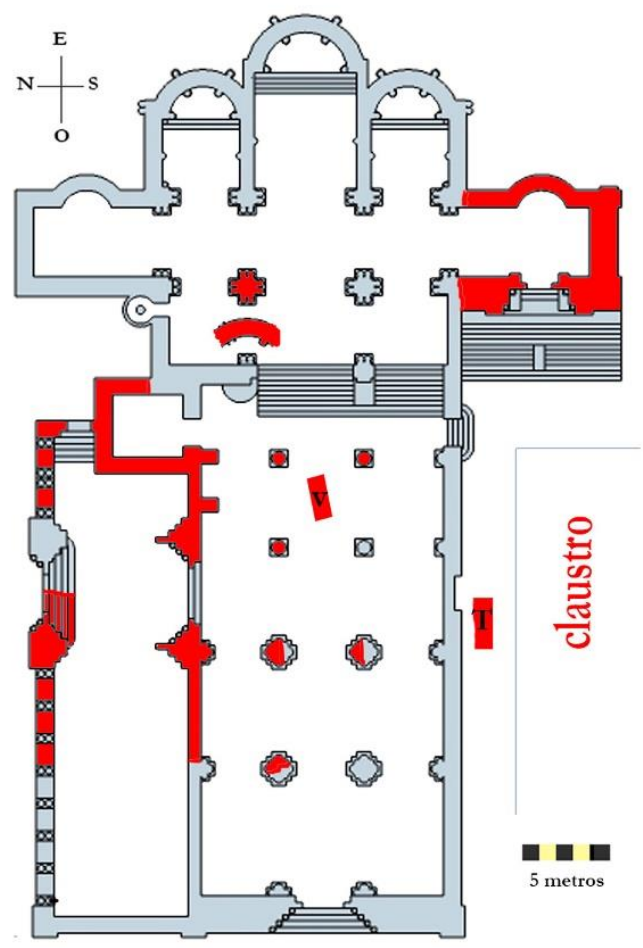

Fig. 1. Restos conservados de la antigua iglesia a los que remitiremos en este trabajo. Dibujo del autor a partir del que publicó Bango (Bango, 1990: 338). "V" tumba del siglo X. "T" primera tumba de Santo Domingo.

al desmontaje de la vieja iglesia ${ }^{7}$. Con todos estos datos se sucedieron hipótesis de reconstrucción que, lejos de ser unitarias, presentan variaciones que intentaremos recoger en nuestro estudio. En 1990 Isidro Bango presentaba un notable trabajo de investigación que incluía plantas y secciones de alguna de sus fases constructivas ${ }^{8}$ y que, desde entonces, ha supuesto la base para las planimetrías silenses ${ }^{9}$. Sin embargo, desde aquella fecha han sido muchas las propuestas historiográficas que han venido a matizar o corregir algunos aspectos que el autor propuso hace cuatro décadas, siendo esa distancia la que nos hace considerar necesaria una actualización de los modelos gráficos y de las conclusiones que llevaban hasta

${ }^{1}$ Palacios, 2000: 303-313.

${ }^{2}$ Sobre la historiografía de la iglesia silense ver: Bango, 1990: 317-322.

${ }^{3}$ Sobre los restos arqueológicos: Bango, 1990. Merino/Reynolds, 2008.

${ }^{4}$ Palacios, 2000: 406-407. Palomero/Palomero, 2013a: 480-481.

${ }^{5}$ Valcárcel, 1982.

${ }^{6}$ Ferotin, 1897.

${ }^{7}$ Para aludir a los informes de Baltasar Díaz remitiremos a la recopilación y traducción que realizaron Félix Palomero e Irene Palomero, ya que consideramos que resulta más accesible que las signaturas originales del archivo silense a las que, a su vez, se remite en ese trabajo: Palomero/Palomero, 2013a.

${ }^{8}$ Este trabajo presentaba plantas de cinco etapas constructivas y una sección: Bango, 1990. Después de esta publicación sólo conocemos un trabajo que haya incluido plantas propias de las diferentes etapas: Palomero/Ilardia/Reyes/Maté, 1999.

${ }^{9}$ Las publicaciones posteriores a 1990 generalmente recurren al empleo de las plantas de Bango, bien de forma directa o bien con aportaciones que toman su propuesta como base: Palacios, 2000: 139. Boto, 2003: 92. Valdez, 2012: 454. 

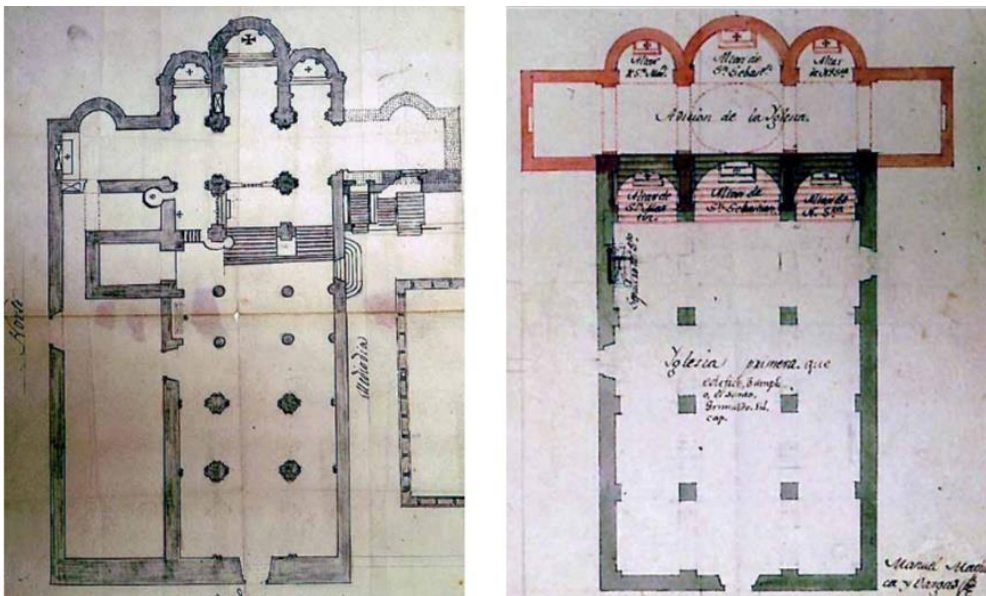

Fig. 2. Plantas del edificio realizadas en el siglo XVIII. Echevarría (izquierda) y Machuca (derecha).

ellos. Por este motivo el objetivo de nuestro trabajo es plantear un nuevo conjunto de reconstrucciones que parta del análisis de la historiografía silense más reciente, tomando de ella las aportaciones que actualmente resultan más ilustrativas para el estudio de los desparecidos templos de Silos. Debido a que el conocimiento de las antiguas iglesias es relativamente fiable para las partes bajas del edificio, pero más impreciso para sus partes altas, hemos optado por plantear la reconstrucción gráfica con dos modelos de representación; las plantas y las secciones, pues intentar presentar un alzado completo de los edificios dejaría más a la imaginación que a los datos objetivos.

En este recorrido nos serviremos, principalmente, de cuatro propuestas historiográficas que serán, por orden cronológico: el referido estudio de Isidro Bango en 1990, las aportaciones de José Luis Senra en 2005, los trabajos de metrología realizados por José Miguel Merino y María Reynolds en 2008 y las propuestas realizadas por Félix Palomero en colaboración con otros autores en los años 1999 y $2013^{10}$. Si bien estas publicaciones citadas no serán las únicas que consideraremos, sí que serán las más reiteradas.

A pesar de este objetivo definido, resultará imposible obviar por completo que esas propuestas de reconstrucción gráfica llevan asociadas, frecuentemente, conclusiones que enlazan con otros debates historiográficos del monasterio en los que la desaparecida iglesia adopta un papel protagonista. Aquellas discusiones historiográficas, cuando surjan, intentaremos exponerlas de forma sintética, justificando siempre nuestra posición respecto a las mismas.

\section{La primera iglesia en el siglo $\mathrm{X}$}

La reconstrucción de la primera iglesia que tuvo el monasterio de San Sebastián de Silos ${ }^{11}$ en el siglo X resulta, sin lugar a dudas, la más compleja de todas las fases constructivas del edificio, pues la escasez de datos de la que se parte ha hecho que cualquier interpretación resulte siempre arriesgada. De hecho, en la larga trayectoria historiográfica del monasterio únicamente destacan dos propuestas para la reconstrucción de este primer templo; por un lado la de Bango, pionera en esta cuestión, que imaginaba una iglesia de nave única dotada

\footnotetext{
${ }^{10}$ Bango, 1990. Senra 2005. Merino/Reynolds, 2008. Palomero/Ilardia/Reyes/Maté, 1999. Palomero/Palomero, 2013a. Las conclusiones de Félix Palomero aparecen recogidas en obras colectivas en las que trabaja junto a otros historiadores y arqueólogos, sin embargo, al ser repetidas por él en diversos artículos y ponencias optaremos por enunciarlas bajo su nombre.

${ }^{11}$ Esa fue su advocación hasta 1125: García de la Borbolla, 2001: 130.
} 
de cámaras laterales y sección semicircular en el interior del ábside y, por otro lado, la de Palomero que proponía un edificio con el mismo núcleo básico de nave única y cabecera cuadrada pero sin los añadidos que había defendido el anterior investigador (fig. 3).
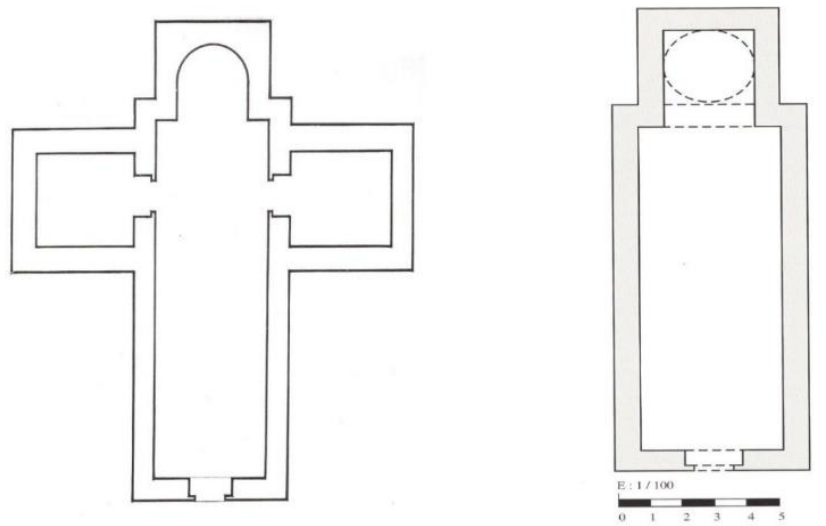

Fig. 3. Propuestas sobre la primera iglesia de Santo Domingo de Silos: Isidro Bango a la izquierda (Bango, 1990: 344) y Félix Palomero a la derecha (Palomero/Ilardia/Reyes/Maté, 1999: 38).
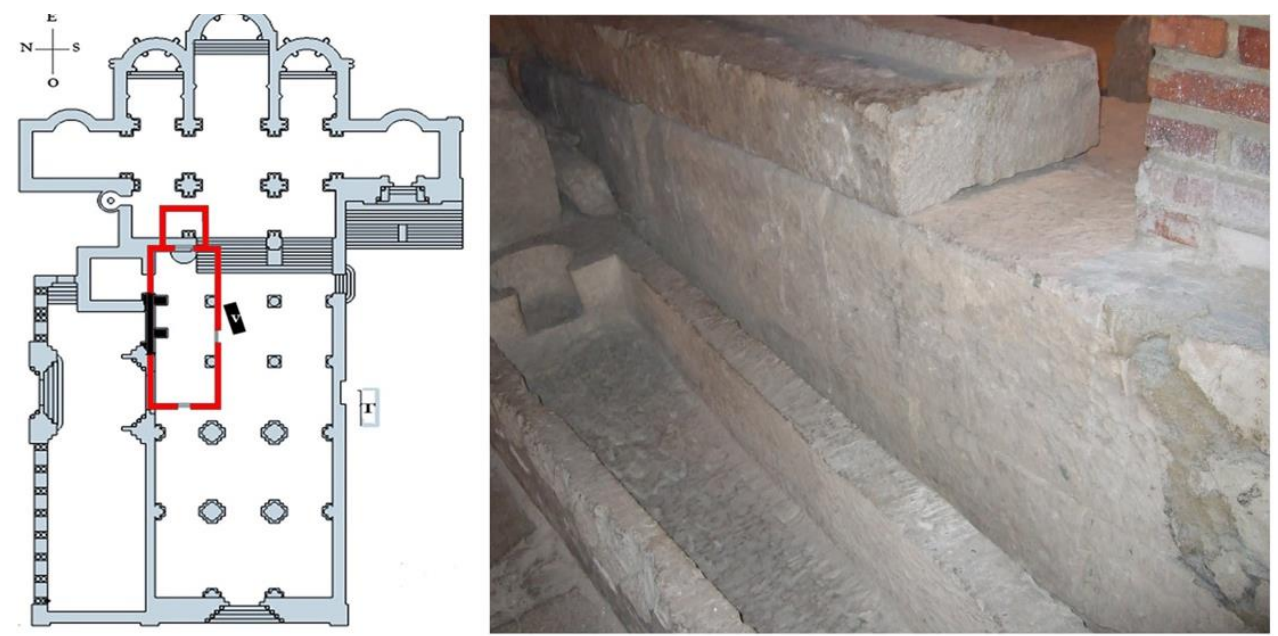

Fig.4. A la derecha la posición de la primera iglesia en el conjunto del templo medieval (tramo de muro conservado y tumba del siglo X marcados en negro). A la izquierda el fragmento de muro altomedieval conservado. Imágenes del autor.

Para llegar a estos modelos los historiadores partían de un enorme vacío documental que apenas permite confirmar que el monasterio existía ya en el siglo $\mathrm{X}$ y no tendría, por entonces, una posición destacada dentro de su territorio, siendo con probabilidad uno más del mosaico de pequeñas fundaciones monásticas que salpicaban su región ${ }^{12}$. Ante esta situación, los historiadores apenas pudieron servirse de un limitado registro arqueológico, en el cual solo un fragmento de muro en el lado septentrional se acepta de forma consensuada como un vestigio del primer templo (fig. 4). A este fragmento debemos sumar los hallazgos y las conclusiones de Vivancos, Del Río y Rivalta ${ }^{13}$ sobre una tumba del siglo X que,

\footnotetext{
${ }^{12}$ Senra llega a plantear la posibilidad de que temporalmente quedase integrado en algún monasterio de mayor entidad: Senra, 2002: 2539.

${ }^{13}$ Vivancos/Del Río/Rivalta, 2003-2005.
} 
originalmente, se encontraba en el exterior de un antiguo edificio y que, después, quedó cubierta por la ampliación meridional (la que analizaremos en el siguiente apartado), lo que significaba, a juicio de los investigadores, que originalmente tuvo que existir un primer edificio de nave única que se ajustaría a los modelos que propusieron Bango y Palomero.

Entre las dos propuestas que podemos valorar para nuestra investigación creemos que la de Bango resulta más aventurada y menos ajustada a la realidad material que conservamos. Este autor consideró que al núcleo básico de la nave y la cabecera debían añadirse las cámaras laterales y un tramo semicircular en el interior del ábside, sin embargo, los restos arqueológicos de aquellas estructuras presentan evidentes diferencias técnicas que no parecen ajustarse al mismo plan de obras que el fragmento de muro prerrománico conservado. $\mathrm{Al}$ respecto, los restos de la cámara norte fueron analizados por Palomero, quien defendió que aquella estancia era un elemento adosado en una etapa posterior y no contemporáneo a los restos del primer edificio ${ }^{14}$, algo que compartimos a partir de nuestras propias observaciones ya que, además de la ruptura del muro para adosar la estancia, observamos la continuidad técnica en la cara externa del paramento, donde no aparecen disposiciones diferentes de los sillares ni recodos que inviten a pensar en la existencia original de otra estructura adosada a él. En relación al sector conservado del ábside (fig. 6) centramos nuestras observaciones en las marcas de herramientas conservadas en los sillares, donde detectamos el empleo de azuelas de filo corto que dejan marcas cóncavas e irregulares en el muro norte y el uso de cinceles diferentes (o al menos una ejecución distinta) en los bloques del ábside, algo que denota el empleo de un utillaje propio en cada sector. Con estos datos nos atrevemos a defender, como ya hicieron otros autores ${ }^{15}$, que ambas estructuras, tanto la cámara norte como el ábside semicircular, responden a momentos constructivos diferentes al del muro prerrománico y no resultaría oportuno considerarlas dentro de un mismo plan de obras.
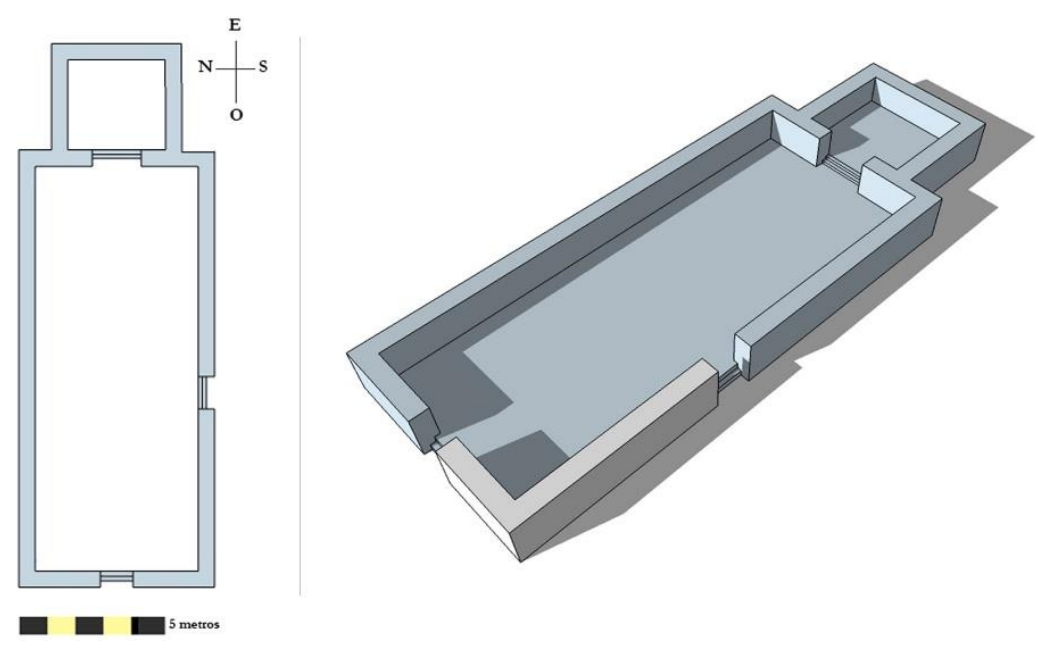

Fig. 5. Planta y sección de la primera iglesia de Silos. Dibujos del autor.

\footnotetext{
${ }^{14} \mathrm{El}$ autor defiende que la cimentación de la cámara norte necesitó, incluso, repicar los sillares del muro de la primera iglesia para adosarse a él, lo considera una prueba de dos fases constructivas diferentes: Palomero/Palomero, 2013a: 490.

${ }^{15}$ Palomero et alii, 1999.
} 
Por otra parte, la interpretación de Palomero, dentro de la dificultad que implica cualquier reconstrucción con datos tan exiguos, la consideramos más prudente, ya que se ajusta a los escasos restos materiales que podemos confirmar en este momento y, además, propone una tipología de iglesia que es común a los edificios cercanos del siglo $\mathrm{X}$ con los que, aparentemente, compartía una misma entidad y unas mismas circunstancias históricas ${ }^{16}$. Por este motivo nos decantamos por esta hipótesis como la base para nuestras propuestas gráficas, ya que constituye un modelo similar al que se utiliza en el entorno cercano de Silos durante la décima centuria.

Una vez elegido el modelo para nuestras planimetrías aún nos quedan por definir dos elementos que debemos incluir en la reconstrucción: la posición de los accesos y la escala del edificio. Respecto a las puertas que pudo tener esta primera iglesia ${ }^{17}$ hemos optado por incluir algunas modificaciones sobre las propuestas históricas del edificio ya que, en primer lugar, creemos adecuado defender la existencia de más de un acceso, pues la mayor parte de las iglesias monásticas altomedievales incorporaron, al menos, una entrada para laicos y otra para el clero ${ }^{18}$. En relación con esta hipótesis debemos tener presente que los edifícios conservados del siglo X cercanos a Silos, con los que compartiría unas mismas circunstancias históricas en este momento, situaron siempre una de esas entradas en el lado meridional ${ }^{19}$, razón por la que resulta coherente proponer una puerta en ese mismo punto, lo que coincidiría con su contexto artístico más próximo. La posición del segundo acceso sí que resulta más variable e imprecisa en los cercanos edificios contemporáneos, sin embargo, en este trabajo hemos optado por representarlo en los pies del templo ya que aquella ubicación, además de ser en la que lo situaron Bango y Palomero, no era extraña en su contexto histórico, apareciendo así en los cercanos edificios altomedievales de San Julián de Lara $^{20}$ o Cueva de Juarros ${ }^{21}$, los cuales se articularon con una entrada meridional y una occidental como proponemos en nuestro modelo gráfico de Silos.

Por último, para establecer la escala y las proporciones del edificio hemos optado, como ya hicieron los dos autores referidos, por tomar como referencia las medidas de los

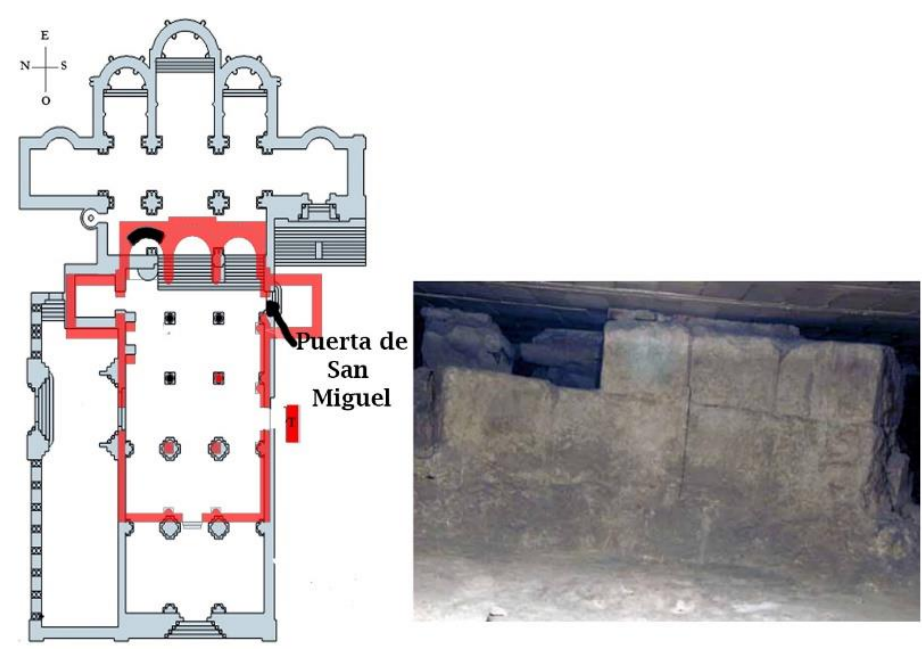

Fig. 6. A la derecha la posición de la iglesia en el conjunto del templo medieval (en negro las partes conservadas e indicada la Puerta de San Miguel). A la derecha el fragmento de ábside conservado. Fotografía de Félix Palomero.

${ }^{16}$ Caballero, 2015: 14. La arriesgada propuesta de Bango, por el contrario, implicaba la aceptación de un modelo de edificio que no se ajustaba a la realidad constructiva de su región y obligaba a establecer complejas relaciones con templos geográficamente lejanos y de entidad muy diferente a la que debía tener el humilde monasterio silense en el siglo X, como los de Recópolis, Leire o Peñalba, los cuales difícilmente pudieron constituir modelos extrapolables al pequeño cenobio silense de la décima centuria: Bango, 1990: 343.

${ }^{17}$ Ante la falta absoluta de datos materiales o documentales optamos por representar esos accesos sin ningún derrame.

\footnotetext{
${ }^{18}$ Moreno, 2018: 71.

${ }^{19}$ Caballero, 2015: 14

${ }^{20}$ Huidobro, 1929.

${ }^{21}$ Pascual / Escribano, 2019.
} 
ábsides de la ampliación del siglo XI, entre los cuales el septentrional pudo haber reaprovechado la cabecera de este primer edificio. Esos datos nos hablarían de una cabecera cuadrada con unos cinco metros en cada lado que, por la proporción habitual de los templos prerrománicos, se uniría a una nave ligeramente más ancha y con una longitud que, con los datos actuales, resulta imposible de definir (fig. 5).

\section{La "Iglesia del Santo" a mediados del siglo XI}

La llegada de Domingo Manso en 1041 supuso un cambio de rumbo en el monasterio que, a juicio de la mayor parte de los historiadores, no tardaría en materializarse en una nueva iglesia, la cual, según los datos aportados por Bango y Elizabeth Valdez, nacía como una ampliación meridional del anterior edificio que pudo estar concluida en $1056^{22}$. Los aludidos estudios de Vivancos, Del Río y Rivalta sobre aquella tumba del siglo X vinieron a confirmar la existencia de dicha ampliación meridional del edificio, ya que demuestran que lo que originalmente era un templo de nave única se convirtió en una iglesia de tres naves que arrasó los antiguos enterramientos situados en su lado sur. Estos datos dejan pocas dudas sobre la existencia de una campaña arquitectónica que supuso la reforma, al menos en anchura, de una construcción anterior.

En el caso de esta iglesia el volumen de los datos conservados cambia radicalmente respecto a los que teníamos para la reconstrucción del primer edificio, pues aquí las referencias documentales empiezan a ser significativas ${ }^{23}$, los restos arqueológicos, como ahora veremos, son más numerosos y contamos, además, con el plano de Machuca orientado a la representación de esta iglesia. Con este panorama se llegó a múltiples propuestas de reconstrucción que organizaremos en cuatro partes: la cabecera, la nave, los accesos y las posibles cámaras laterales.

La cabecera de este edificio fue derribada durante la primera ampliación románica pero afortunadamente sus restos arqueológicos salieron a la luz en 1776 durante la construcción de la nueva iglesia neoclásica y fueron minuciosamente descritos en su momento, lo que nos permitió conocer su forma interna semicircular, las dimensiones de sus altares y las monedas enterradas bajo ellos ${ }^{24}$. Aquellas estructuras, de las que conservamos el pequeño tramo semicircular del ábside norte al que antes aludimos (fig. 6), debieron ser conocidas en el siglo XVIII, directa o indirectamente, por Manuel Machuca ya que es la tipología que trasladó de forma precisa a su plano de la iglesia (fig. 2). Con aquellos datos documentales la historiografía silense definió el espacio de una forma consensuada como una cabecera triple con ábsides rectos al exterior, forma semicircular interna y medias columnas en los muros divisorios. De esta forma unitaria se recoge en los planos de Bango, Senra y Palomero (fig.7), y será, por tanto, la que traslademos a nuestra propuesta sin variaciones.

Respecto a la nave del edificio hemos conservado, a nivel arqueológico, el arranque de tres pilares cilíndricos, los cuales se mantuvieron en las posteriores ampliaciones románicas y fueron representados en el plano de Echevarría $^{25}$. La existencia de este registro arqueológico hizo que los algunos investigadores como Román Sáiz, Bango o Palomero en sus primeros estudios ${ }^{26}$, apostasen por un edificio de planta cuadrada que estaría centralizado por esos soportes y que, a su juicio, no podría prolongarse más hacia los pies por aparecer allí los pilares de la ampliación tardorrománica. Aquella propuesta, sin embargo, convivía con

\footnotetext{
${ }^{22}$ En esa fecha se cita por primera vez la triple advocación de los nuevos ábsides: Bango, 1990: 325 y 342. Valdez alude a la mayor anchura de la nave norte respecto a la central como una posible evidencia de ese proceso de ampliación: Valdez, 2012: 20.

${ }^{23}$ García, 1990: 31-67.

${ }^{24}$ Senra, 2005: 333-335.

${ }^{25}$ Ese plano representaba cuatro pilares, de los cuales uno se ha perdido por completo. Según los datos de Bango tendrían un diámetro de 0,90 metros: Bango, 1990: 338. Una imagen publicada en abierto en: Palomero/Palomero, 2013b: 171, figura 10.

${ }^{26}$ Esos planos, en el mismo orden que se citan, en: VV.AA., 1973: 72. Palomero et alii, 1999: 41. Bango, 1990: 350 .
} 
la interpretación de otros autores que, como sucede en el plano de Machuca, optaban por defender un edificio rectangular, siendo esa tipología la que retomaron Senra y Palomero gracias a los datos documentales recogidos por Baltasar Díaz durante el desmontaje de la fachada tardorrománica ${ }^{27}$. Dentro de las propuestas de estos autores nos sentimos más cercanos a la interpretación que hizo Senra, el cual defendía la existencia de un tramo más en la nave, algo que justificaba por la similitud con el plano de Manuel Machuca ${ }^{28} \mathrm{y}$, sobre todo, por la longitud del primer proyecto del claustro anexo, cuyas dimensiones originales coincidirían con una hipotética iglesia de tres tramos ${ }^{29}$. Esa posible relación entre la longitud del antiguo templo y el proyecto original del claustro también ha sido planteada por Boto y $V_{\text {Valde }}{ }^{30}$, quienes defendieron esa misma dependencia entre la longitud de los dos proyectos arquitectónicos, apoyándose la segunda autora en las referencias documentales de Baltasar Díaz. La idea de que ambos espacios monásticos pudieron correr en paralelo tiene toda la lógica constructiva si pensamos en la mayor parte de los monasterios románicos, encontrándose aquí reforzada por el hallazgo de aquellos tambores que sugieren una mayor longitud del templo y por la existencia de un proyecto original del claustro coincidente con esa longitud, motivo por el que valoramos aquellas propuestas como las más fiables para ser trasladadas a nuestro plano ${ }^{31}$.
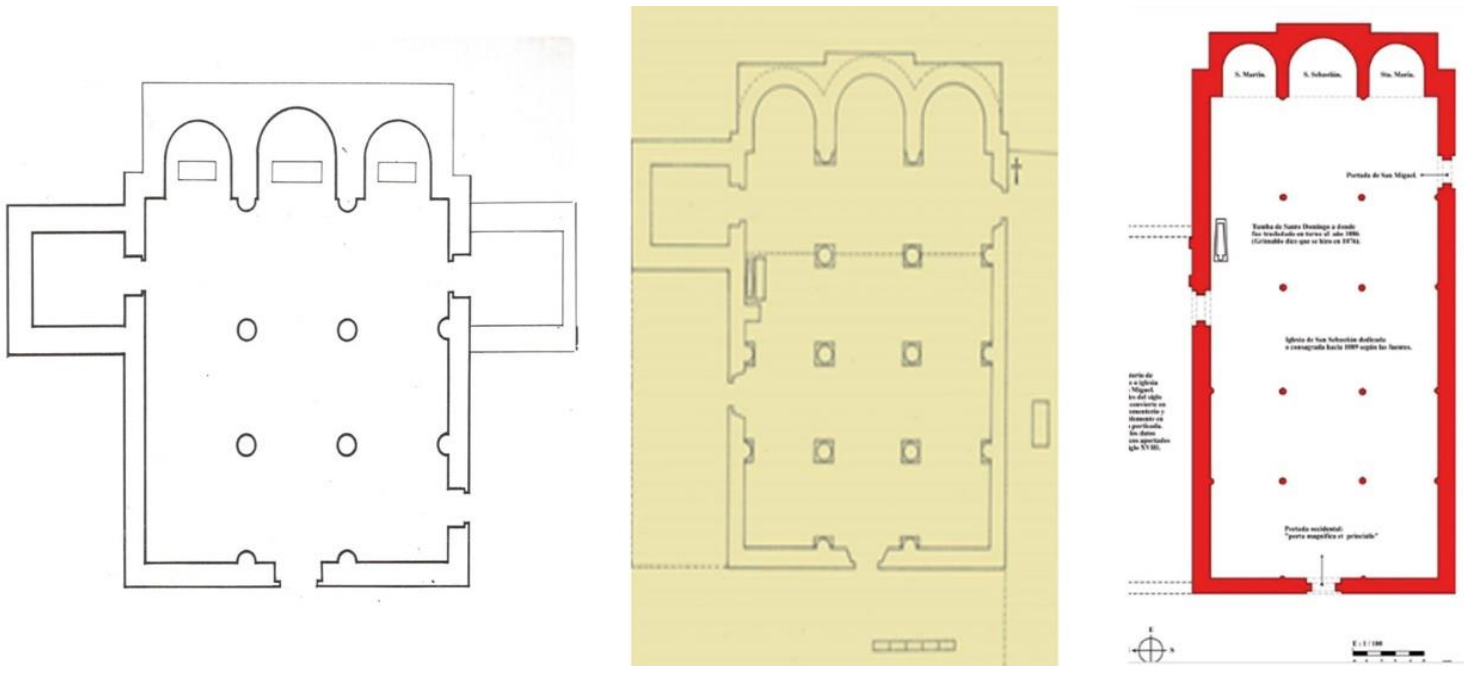

Fig. 7. Propuestas sobre el segundo templo: Bango a la izquierda (Bango, 1990: 350), Senra en el centro (Senra, 2009: 199) y Palomero a la derecha (Palomero/Palomero, 2013b: 165).

Respecto a las entradas que pudo tener este templo del siglo XI contamos con más datos que en el anterior caso. En el lado sur tenemos constancia documental de la existencia de

${ }^{27}$ Baltasar Díaz documentó el hallazgo de capiteles similares a los de este edificio utilizados como material de relleno en la fachada del siglo XII, lo que indicaría que originalmente debieron existir más columnas además de las cuatro conocidas: Senra, 2005: 342-343. Palomero/Palomero, 2013a: 487-488.

${ }^{28}$ Machuca llegó a conocer parte del edificio en alzado, por lo que su planta no debe atribuirse a un mero convencionalismo, sino que pudo tener más datos de los que hoy conocemos con los restos arqueológicos.

${ }^{29}$ Senra, 2005: 343.

${ }^{30}$ Boto, 2003: 126. Valdez, 2012: 18-19.

${ }^{31}$ Palomero defendía una longitud mayor del edificio basándose en el hallazgo documentado de "seis capiteles" reutilizados en la fachada. En este trabajo, sin embargo, creemos que aquellas piezas no deben valorarse necesariamente como sinónimo de más tramos en el edificio, pues perfectamente pudieron proceder de los apoyos laterales de los muros, los cuales también fueron desmontados durante la ampliación románica. 
dos accesos: por un lado una puerta cerca del ángulo oriental denominada de "San Miguel" (indicada en la figura 6) que al menos desde el siglo XVI actuaba como conexión con el claustro y, por otro lado, la "puerta de la iglesia" que fue citada por Grimaldo en el siglo XI como punto frente al que se enterró a Domingo Manso ${ }^{32}$ y que se encontraría, aproximadamente, en un arcosolio moderno situado actualmente en el centro de la panda norte del claustro ${ }^{33}$. Estas dos entradas fueron representadas en los planos de Georges Gaillard $^{34}$ y Bango, sin embargo, una corriente de opinión diferente optó por rechazar la existencia del acceso citado por Grimaldo, defendiendo que dicha puerta documentada debía ser la de San Miguel y que la tumba del santo se habría desplazado al centro de la panda claustral en un momento posterior ${ }^{35}$. Dentro de este debate existe una referencia documental que no ha sido valorada con la suficiente atención, nos referimos a una noticia del año $1754^{36}$ en la que era tabicado un arco frente a la tumba del santo (aproximadamente donde hoy se abre el arcosolio moderno), el cual coincidía con la posición en la que Grimaldo había aludido a la entrada y en la que Gaillard y Bango habían situado la puerta de sus planos. Este dato nos parece sugerente, ya que la existencia de un arco calado en ese punto del muro de la iglesia nos puede estar remitiendo a un vestigio de aquella antigua entrada, lo que hace que consideremos adecuado plantear allí su existencia. Sobre la funcionalidad de estos accesos volveremos más adelante.

Respecto a las otras entradas que pudo tener el templo no hemos conservado referencias explícitas, pero hemos decidido incorporar, como en los planos de Senra y Palomero, una más en el lado norte y otra a los pies. Respecto a la decisión de incluir un acceso en el lado septentrional nos hemos basado en la existencia allí de una puerta tardorrománica que genera una simetría perfecta con la que proponíamos frente a la tumba del santo y que podría haberse servido de un acceso anterior abierto en esta iglesia del siglo $\mathrm{XI}^{37}$. La existencia de un ingreso en este lado puede justificarse también por cuestiones funcionales, ya que el núcleo de población silense se situaba en este extremo y, al menos desde el siglo XII, tenemos evidencias del uso de la puerta norte como la entrada de los fieles a la iglesia ${ }^{38}$. Respecto a la puerta de los pies decidimos representarla por la nueva posición político-administrativa que el monasterio había adquirido en este momento y que lo había elevado a uno de los principales centros monásticos del oriente castellano, una circunstancia que hace posible la existencia de una entrada de carácter oficial en poniente que resultó común en los centros monásticos de la región desde la segunda mitad del siglo XI ${ }^{39}$

El último aspecto que vamos a valorar en esta iglesia es la posible presencia de estancias laterales junto a la cabecera, cuya existencia se plantea por haber conservado la cimentación de una cámara en lado norte, la cual fue utilizada como sacristía y base del campanario desde el siglo XII. Esta estancia plantea un interesante debate historiográfico sobre su origen y funcionalidad que ha llevado a tres propuestas diferentes: por un lado la de aquellos investigadores que desligan su construcción del edificio altomedieval y la consideran como la base del campanario realizado siglo XII, por otro lado los que piensan que pudo existir en

32 “intra claustrum fratrum, ante portas eclesie": Valcárcel, 1982: 308. Ese enterramiento se sitúa, actualmente, frente al capitel 23 del claustro, muy cerca del centro de la panda norte: Valdez, 2003.

${ }^{33}$ Valdez, 2012: 454.

${ }^{34}$ Gaillard, 1932: 67.

35 Orduña, 2015: 19. Senra lo representaba así en su plano de 2009 (fig. 7), sin embargo, en otras publicaciones cita la existencia del segundo acceso: Senra, 2002: 2555; 2005: 342.

${ }^{36}$ Palacios, 2000: 115.

${ }^{37}$ Esta posibilidad también es planteada por Bango, aunque no llegó a trasladarla al plano: Bango, 1990: 349 , nota 186.

${ }^{38}$ Boto, 2003: 138.

${ }^{39}$ La entrada principal a los pies del templo la encontramos en los cercanos monasterios de San Pedro de Arlanza, a finales del siglo XI, o en los de San Quirce de los Ausines y San Millán de Lara, ya en la centuria siguiente. 
este momento pero que, por imaginar el enterramiento del santo frente a la puerta opuesta, no tendría una cámara similar en el lado sur y, por último, los que defienden que la estancia norte debía tener una simétrica en el lado contrario ${ }^{40}$. Dentro de este debate creemos que la primera postura, la que considera la estancia como el campanario del siglo XII, debe descartarse por la coincidencia exacta de la cimentación con el ángulo del antiguo edificio prerrománico, lo que parece indicar que cuando se planifica aún no existía la ampliación románica ${ }^{41}$. Respecto a la segunda postura debemos recordar que la posición de la tumba del santo frente a la puerta de San Miguel, que impedía considerar una construcción en este punto, ya la descartamos en los párrafos anteriores, por lo que no sería argumento para rechazar su existencia.

Nuestra posición frente al debate, por tanto, se vincula a los modelos propuestos por Gaillard y Bango, lo cuales imaginaron dos estancias simétricas que serían reflejo de un transepto, para el primero, y cámaras propias de la liturgia hispana para el segundo. Sobre su hipotética existencia Bango valoró el derrame opuesto de la puerta de San Miguel en el plano de Echevarría y la simetría exacta de aquella entrada con la que llevaba a la estancia septentrional ${ }^{42}$, unos argumentos a los que deberíamos sumar las cuestiones funcionales derivadas de la existencia de la segunda puerta meridional frente a la tumba del santo de la que antes hablamos. Esa segunda entrada fue documentada por Grimaldo en el siglo XI como el acceso de los monjes a la iglesia, un dato que nos obliga a considerar que la puerta de San Miguel, situada apenas a cinco metros de aquella, debía tener una funcionalidad distinta, en la cual podría encajar su uso como paso a una hipotética estancia desaparecida. La existencia de aquellas dos puertas tan cercanas entre sí y la certeza de que la occidental era el ingreso de los monjes al claustro, hace que nos decantemos por defender esa hipotética cámara meridional que daría sentido funcional a la puerta que hoy conocemos con el nombre de San Miguel, siendo así como lo trasladamos a nuestros planos ${ }^{43}$ (fig. 8).

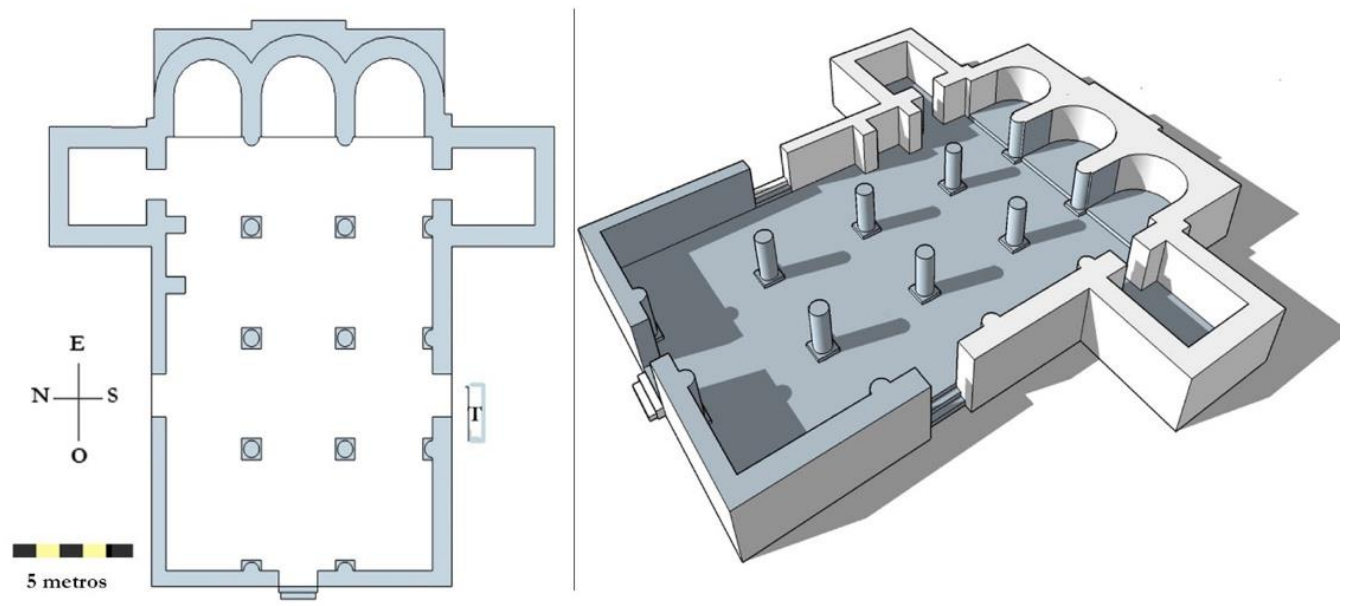

Fig. 8. Planta y sección de la iglesia del siglo XI. Dibujos del autor.

${ }^{40}$ Sobre estas tres interpretaciones recomendamos ver las propuestas de la figura 7, cada una de las cuales responde a uno de estos planteamientos.

${ }^{41}$ Palomero indicaba que esa posición del campanario es habitual en la región, sin embargo, la observación debe matizarse pues las torres septentrionales cercanas rara vez aparecen desplazadas hacía el centro de la nave y nunca se separan de su cuerpo de escaleras. Resulta más probable, como defendiese Bango, que la colocación de la torre esté condicionada por alguna estructura previa. Palomero et alii, 1999: 40-41.

42 Bango, 1990: 348-349.

43 La construcción del claustro románico tuvo que implicar necesariamente el derribo de aquella hipotética estancia. En ese momento la presencia de dos entradas cercanas entre sí pudo llevar a priorizar la de San Miguel, más cercana al coro, y provocar el desuso de la otra. 


\section{La ampliación oriental. Primera intervención románica}

La ampliación oriental de la antigua iglesia del santo fue la primera obra románica del edificio. La mayor parte de la historiografía reciente coincide en separar esta intervención de la construcción del transepto, el cual sería un espacio añadido tras un paréntesis constructivo que, según los casos, se considera más o menos amplio ${ }^{44}$. Para la datación de esta construcción contamos con dos fechas extremas: por un lado la documentada consagración de $1088^{45}$ y, en el otro extremo, la adición del transepto cerca del $1125^{46}$. Esa última referencia temporal goza de un amplio consenso de los historiadores como fecha post quem en la que el cuerpo oriental ya debía hallarse finalizado, sin embargo, la imprecisa consagración de 1088 ha convertido su datación en uno de los principales debates sobre la antigua iglesia, pues algunos historiadores han vinculado la ceremonia al antiguo templo altomedieval gracias al hallazgo de las monedas conmemorativas bajo sus altares y han descartado, de esta forma, que existiera por entonces la ampliación oriental ${ }^{47}$, mientras que otros han preferido relacionarla con unas hipotéticas obras románicas que estarían avanzadas pero aún sin uso ${ }^{48}$. Estas discrepancias nacen del complejo carácter de la ceremonia documentada, pues aquella parece estar más relacionada con el deseo de trasladar al monasterio a la poderosa comitiva que la ofició que con el propio estado del edificio, ya que la consagración no se ajusta de forma precisa a ninguna de las dos construcciones, pues el templo altomedieval llevaba varias décadas en pie y el románico, en caso de existir en este momento, aún estaría inconcluso y sin altares. Esta situación ha hecho que, en cualquiera de las opciones, los historiadores hayan tenido que buscar argumentos que justifiquen sus posturas y lo que era una referencia temporal objetiva termine convirtiéndose en objeto de arduo debate.

En relación a estas cuestiones nuestra postura sobre la datación del edificio intenta alejarse de cualquier planteamiento hipotético y valora, únicamente, aquellos datos que podemos considerar objetivos. En esta línea la única certeza que tenemos es que la ceremonia de consagración tuvo lugar en los altares del templo altomedieval que antes comentamos ${ }^{49} \mathrm{y}$, por tanto, es aquel edificio el que se hallaba en uso en el año 1088, careciendo de cualquier dato documental o material que permita presuponer la existencia de obras románicas ya iniciadas. Nuestra lectura, en este sentido, defiende que la ampliación oriental románica debe considerarse, a falta de más datos, posterior a la fecha de aquella consagración documentada, pues plantearlo de otra forma sería entrar en un terreno hipotético que carece de cualquier respaldo documental que lo avale.

Las propuestas que intentan defender la existencia de este edificio en 1088 se encuentran, en gran medida, condicionadas por aquellas corrientes historiográficas que defendieron que esta ampliación oriental del templo debía ser anterior a la obra del claustro, por lo que una datación temprana del patio obligaba a retrotraer la fecha de la iglesia, como poco, a finales del siglo $\mathrm{XI}^{50}$. Esta dependencia entre el claustro y la ampliación oriental ha sido, a nuestro juicio, frecuentemente sobrevalorada, ya que realmente nos hallamos ante proyectos

${ }^{44}$ La propuesta de dos intervenciones constructivas diferentes se basa en la existencia de una irregular costura conservada entre los dos cuerpos que, para la mayor parte de los autores, es el reflejo de una interrupción temporal de las obras. Sobre este debate, y con una imagen de la costura, recomendamos: Senra, 2009: 206-207.

${ }^{45}$ A esta consagración se consiguió trasladar a una importante comitiva desde el concilio de los Husillos: el cardenal Ricardo, el arzobispo Bernardo de Toledo, el obispo Pedro de Aix-en-Provence, el obispo Raimundo de Roda y el obispo Gómez de Burgos: Valdez, 2012: 35-36.

${ }^{46}$ En el siguiente apartado presentaremos con más detalle los argumentos para la datación de este cuerpo.

${ }^{47}$ Senra, 2005. Palomero/Palomero, 2013a.

48 Bango, 1990.

${ }^{49}$ Senra, 2005: 333-336.

${ }^{50}$ Sobre las corrientes historiográficas que defienden la anterioridad de la iglesia alta respecto al claustro recomendamos: Boto, 2003: 91-99. 
independientes que no aparecen condicionados entre $\mathrm{s}^{51}$ y la cronología de uno no debe, necesariamente, repercutir sobre la del otro. Por tanto, ese carácter precedente de la ampliación oriental resulta un planteamiento encorsetado y carente de respaldo documental, ya que la secuencia constructiva del monasterio perfectamente pudo iniciarse antes en las pandas claustrales y trasladarse después a la iglesia, sin que la cronología del patio tenga que verse modificada por ello ${ }^{52}$. De esta forma, la idea de que la iglesia románica tenía que existir en 1088 como respaldo para la datación temprana del claustro no resulta necesaria para una coherente secuencia constructiva del monasterio.

Esta primera iglesia románica, pasando ya a las cuestiones estructurales que nos atañen para este trabajo, era una ampliación oriental del antiguo edificio que supuso el derribo de la cabecera prerrománica y dio lugar a un nuevo cuerpo arquitectónico que, por los condicionantes geológicos, tuvo que construirse dos metros por encima del antiguo templo y conectado a él por una amplia escalera, dando lugar a las denominaciones de "iglesia baja" (que hace referencia al edificio prerrománico) e "iglesia alta" (que es la ampliación románica). El primer aspecto que debemos valorar es la alineación que se generó entre los dos edificios, donde Bango afirmaba haber detectado una desviación en el eje que resultaba sugerente para explicar la asimetría de las pandas claustrales y que, en consecuencia, llegó a ser valorada en posteriores publicaciones ${ }^{53}$. El dato, sin embargo, ha sido cuestionado en estudios más recientes que, con un apoyo técnico más preciso pusieron en duda la existencia de dicha desviación, siendo así apuntado tras las mediciones que llevaron a cabo Palomero y Téllez ${ }^{54}$ y confirmado por los precisos estudios de metrología de Merino y Reynolds. Estos últimos investigadores, arquitectos de formación y profesión, utilizaron recursos y técnicas más precisos que los que se habían aplicado hasta entonces y consiguieron, de esta forma, calcular los ángulos y las desviaciones de cada elemento arquitectónico conservado, llegando a rechazar de forma contundente la existencia de una asimetría entre ambos edificios ${ }^{55}$. Por este motivo, decidimos representar nuestros planos con una correcta alineación de los dos cuerpos de la iglesia y consideramos adecuado descartar aquella supuesta desviación que ha arrastrado consigo otros modelos planimétricos posteriores, pues los recursos y técnicas empleados por los citados autores resultan más precisos que los instrumentos que se utilizaron en las mediciones previas.

Para la reconstrucción de esta primera intervención románica los historiadores se han servido, principalmente, del minucioso plano de Echevarría, ya que a nivel arqueológico apenas se conserva el arranque de un pilar cruciforme ${ }^{56}$. Con esta fuente común el modelo de reconstrucción para el cuerpo de la iglesia, al margen de la cabecera, resulta bastante unitario y su representación es muy similar en todos los planos que se han realizado sobre el edificio. Aquí, los diferentes investigadores coinciden en identificar un cuerpo central con cuatro pilares con columnas dobles en sus frentes, los cuales muestran una tipología de soporte que ha servido de argumento para diferentes propuestas cronológicas sobre la iglesia ${ }^{57}$. En el eje central de este cuerpo existía una cúpula que fue documentada por

${ }^{51}$ Senra defendía la relación del claustro con la iglesia baja y no con esta ampliación: Senra, 2009: $207-$ 208. Valdez, por su parte, hablaba de un "absoluto divorcio" entre el claustro y la ampliación oriental: Valdez, 2012: 177.

${ }^{52}$ Nuestra postura en este debate se inclina hacia ese orden constructivo: primero se hicieron las pandas del claustro y después la ampliación oriental de la iglesia. Esta secuencia ya fue planteada por Senra, con el que compartimos el orden constructivo, pero no ciertos matices cronológicos, especialmente su propuesta de retrasar la fecha de construcción del transepto: Senra, 2005.

${ }^{53}$ Bango, 1990: 355. Otras publicaciones que llegaron a valorar ese dato: Boto, 2003: 94. Senra, 2009 : 225.

${ }^{54}$ Palomero et alii, 1999: 55.

${ }^{55}$ Merino/Reynolds, 2008: 558.

${ }^{56}$ La imagen de ese pilar en abierto en: Palomero/Palomero, 2013b: 172, figura11.

${ }^{57}$ La tipología de soporte resulta poco frecuente durante el siglo XI, algo que obligó a Bango (defensor de esa cronología) a establecer paralelos muy puntuales con otros edificios hispanos de ese momento. Para 
Jerónimo Nebreda y representada en los planos de Machuca y Echevarría, la cual, por las repetidas alusiones a ella como "ochavo", pudiera interpretarse al exterior como un cimborrio octogonal ${ }^{58}$. En relación a este cuerpo central de la ampliación románica no hemos encontrado posibles aportaciones personales que pudieran modificar lo ya expuesto por otros autores.

La cabecera sería la última estructura que nos queda por definir en el edificio y para ello no tenemos más datos que el plano de Echevarría, el cual representaba el sector como una cabecera de tres ábsides con medias columnas adosadas tanto al interior como al exterior, siendo el central más ancho y profundo que los laterales y contando, además, con un amplio presbiterio rectangular rematado por un tramo semicircular. Para la interpretación de este sector hemos decidido tomar en consideración las reflexiones y propuestas de Senra ${ }^{59}$ y los modelos planimétricos de Merino y Reynolds ${ }^{60}$ que son, a nuestro juicio, quienes lo han analizado con una mayor fidelidad a la fuente original y han rechazado, en consecuencia, las licencias que otros autores tomaron en la representación de este sector. Los citados investigadores, ante la falta de cualquier vestigio material en esta parte del edificio, optaron por considerar la cabecera de la misma forma que fue representada en el plano de Echevarría, una opción que debe considerarse como válida al ser la única fuente de referencia que tenemos para su conocimiento. Por tanto, no creemos adecuado que puedan establecerse en este sector variaciones que se alejen de lo representado en aquel plano del siglo XVIII, pues ese caso estaríamos cayendo en especulaciones que se alejarían de la única referencia fiable para su reconstrucción. (fig. 9).
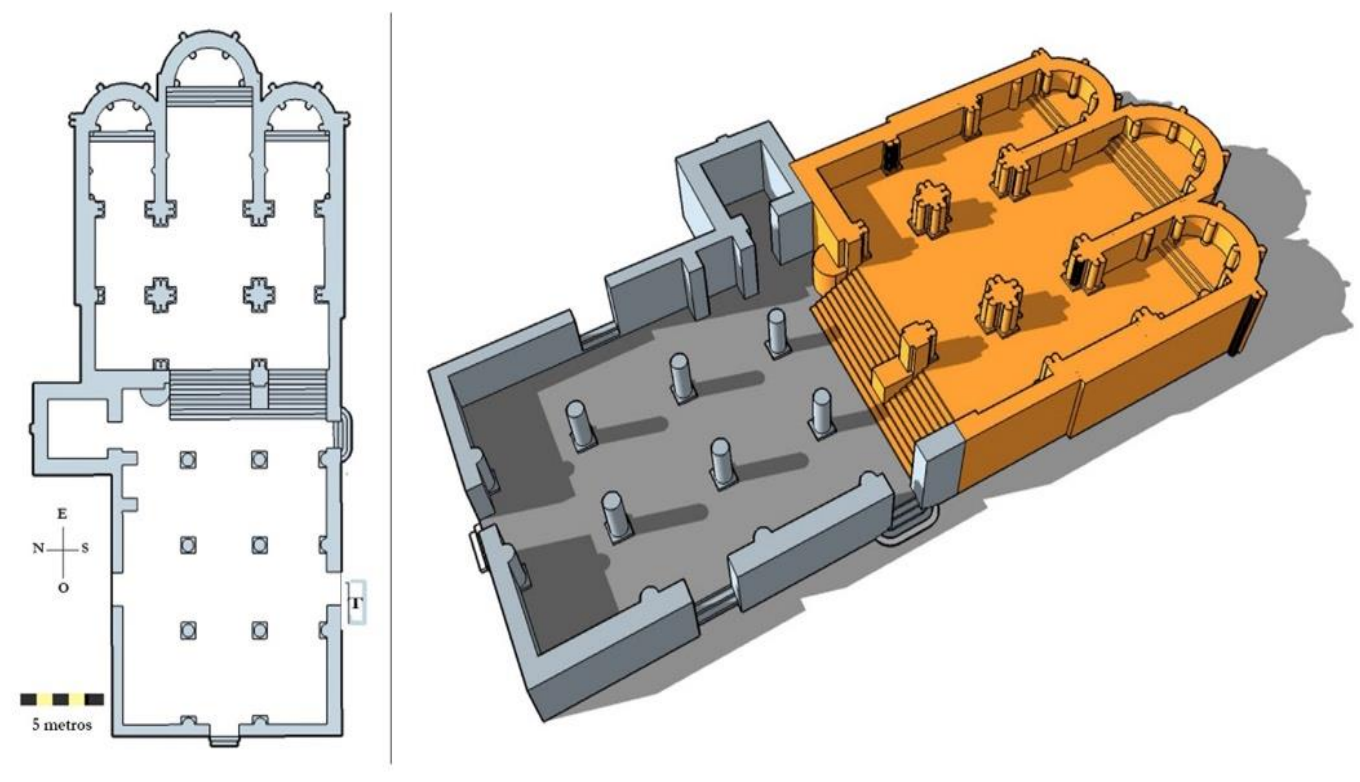

Fig. 9. Planta y sección de la ampliación oriental. Dibujos del autor.

Senra la difusión de ese modelo de pilar resulta más frecuente en la duodécima centuria: Bango, 1990. Senra, 2005.

${ }^{58}$ Bango, 1990: 361-362.

59 Senra, 2005: 349-351.

${ }^{60}$ Merino/Reynolds, 2008: 562. 


\section{La construcción del transepto.}

Siguiendo la secuencia constructiva que tomamos como referencia en este trabajo, la siguiente intervención en la iglesia monástica serían los brazos del transepto que se añadieron al templo cerca del año $1125^{61}$. El brazo meridional, reaprovechado como entrada de la capilla barroca, ha llegado hasta nosotros completo, lo cual permite una reconstrucción fiable que deja pocos resquicios, a nivel estructural, para las aportaciones personales. Esta construcción románica es un espacio rectangular, de 7,95 x 5,60 metros $^{62}$, dotado de un pequeño absidiolo en el muro oriental y con una portada, conocida como Puerta de las Vírgenes, en el lado occidental $^{63}$. Aquel acceso era la conexión de la iglesia con el claustro, cuya unión se generaba a partir de una amplia escalinata que actualmente cuenta con modernas transformaciones.

El desaparecido brazo septentrional, a juzgar por el plano de Echevarría, debía ser simétrico al que conservamos y únicamente difiere de éste en la ausencia de un acceso desde el exterior. La puerta que aparece documentada en su lado occidental es una intervención del siglo XVI que se hizo para unir la iglesia con el relicario construido en el exterior y que no existía en el proyecto original del edificio que aquí analizamos ${ }^{64}$.

La construcción del transepto, más allá de las cuestiones estructurales, adquiere una especial importancia por ser una referencia temporal que ha ayudado a la datación de las primeras obras del claustro. La fecha de aquellos primeros relieves del patio ha sido uno de los principales campos de batalla de la historiografía silense, pues desde los primeros años del siglo XX se inició un enfrentamiento entre los defensores de su datación temprana (finales del siglo XI) y aquellos que pretendían retrasarlos varias décadas, el cual era en realidad un debate sobre la autonomía o dependencia del románico hispano respecto al francés. En la actualidad el trasfondo de aquella discusión ha quedado superado, pero aún siguen vigentes dos líneas de interpretación que sitúan estas obras, según los casos, en el entorno del año 1100 o en el segundo cuarto del siglo XII ${ }^{65}$. En este debate el transepto ha resultado un elemento fundamental, pues su edificación cerca de 1125 supuso el derribo de parte de las estructuras claustrales que se encontraban ya construidas, lo que parece evidenciar el carácter precedente de la obra del patio respecto a la del transepto ${ }^{66}$.

En este contexto la secuencia constructiva resulta, a nuestro juicio, relativamente clara y no encontramos argumentos convincentes que pudieran sugerir que las arquerías del claustro se hicieron después del transepto, a pesar de que existen algunas investigaciones que intentaron justificarlo de esa manera ${ }^{6 t}$. Del mismo modo, la compleja escalera que se construye y la destrucción de dependencias monásticas previas deja claro, como antes expusimos, que los proyectos de la ampliación oriental y el claustro se hicieron de forma independiente el uno del otro y no plantearon en origen, ni siquiera, una futura unión directa entre ambos espacios, por lo que la dependencia cronológica de uno respecto al otro no debe valorarse de forma tan determinante como a veces se ha hecho.

$\mathrm{Al}$ margen de este debate historiográfico orientado a la datación de las obras claustrales, y volviendo a las cuestiones estructurales que afectan a nuestros planos, debemos remarcar que en el caso del transepto nos hallamos ante una referencia objetiva donde apenas existen variaciones o propuestas dispares que pudiéramos aportar en este estudio, ya que la edificación ha sido representada de la misma forma en todas la propuestas planimétricas que

${ }^{61}$ La mayor parte de los investigadores, a partir de la relación escultórica con los capiteles de San Pedro de Dueñas, proponen una horquilla que oscila entre 1120 y 1130: Moralejo, 1990: 211. Klein, 1990: 299.

${ }^{62}$ Bango, 1990: 341.

${ }^{63}$ Sobre esta portada, ver: Klein, 1990. Moralejo, 1990.

${ }^{64}$ Palacios, 2000: 151-156.

${ }^{65}$ Sobre las diferentes propuestas para la datación del claustro recomendamos: Boto, 2003.

${ }^{66} \mathrm{Al}$ defender este transepto y la iglesia alta como estructuras posteriores al claustro nuestra posición en el debate nos lleva a situar las primeras obras del patio en ese entorno del año 1100 en el que se han posicionado la mayor parte de los autores recientes: Boto, 2003.

${ }^{67}$ Klein, 1990. Moralejo, 1990. 
se han hecho sobre el templo y, del mismo modo, es como lo trasladamos a nuestros planos (fig. 10).
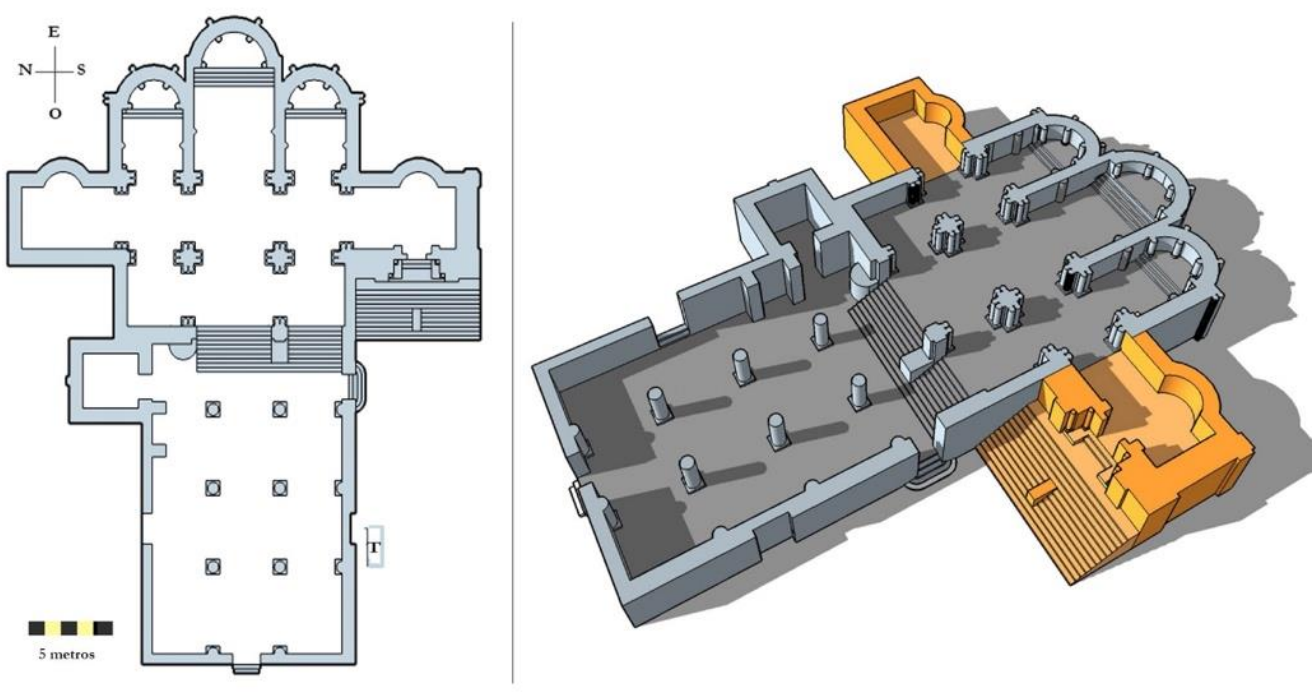

Fig. 10. Planta y sección con la construcción del transepto. Dibujos del autor.

\section{La ampliación occidental y la torre}

La siguiente intervención en la iglesia es una ampliación occidental que, a partir del antiguo templo prerrománico, aumentó la longitud del edificio hacia los pies y construyó una nueva fachada. Este proceso constructivo puede relacionarse con la segunda campaña de obras del claustro, ya que la ampliación de las galerías del patio parece realizarse en paralelo al crecimiento de la iglesia ${ }^{68}$, lo que nos llevaría a una datación que, teniendo en cuenta las segundas obras claustrales, podría ser cercana a la mitad del siglo XII ${ }^{69}$. Esta cronología aparece apoyada también por la construcción de la puerta septentrional cerca de la década de 1170 (hablaremos de ella con detalle en el siguiente apartado) que tuvo que romper el muro de esta ampliación occidental y recolocar los sillares para adaptarse a él $1^{70}$, lo que nos permite saber que en ese momento la intervención de los pies ya había finalizado y nos sirve como fecha post quem para su datación.

De la ampliación occidental hemos conservado, a nivel arqueológico, un tramo del muro norte y el arranque de tres pilares compuestos ${ }^{71}$. Con estos restos, y con el plano de Echevarría, la intervención puede definirse como una ampliación o reforma de dos tramos en el lado occidental del antiguo templo prerrománico, representándose de esa forma en todos los planos que se han hecho sobre la iglesia. En esta ampliación la estructura menos conocida, como ya indicaba Boto $^{72}$, es la fachada que se levantó a los pies, para cuya reconstrucción estructural únicamente contamos con un plano de Román Sáiz ${ }^{73}$ que representaba una portada abocinada con cuatro columnas a cada lado y que, pese a poder ser

\footnotetext{
${ }^{68}$ Boto, 2003: 138. Senra, 2005: 342-343.

${ }^{69}$ Esther Lozano indica que en el año 1158 debía hallarse en construcción la segunda parte del claustro y alude a una datación similar en autores como Valdez o Boto: Lozano, 2010: 197-198 y nota 3.

${ }^{70}$ Esa ruptura del muro occidental se observa en las antiguas fotografías de la excavación de 1964: Bango, 1990: 370-371.

${ }^{71}$ Merino/Reynolds, 2008: 557.

${ }^{72}$ Boto, 2003: 135-137.

${ }^{73}$ Pérez, 1955.
} 
un convencionalismo ${ }^{74}$, decidimos mantener en nuestra reconstrucción ante la ausencia de más datos ${ }^{75}$.

Respecto a los demás accesos, y descartando que la aludida portada tardorrománica del lado septentrional sea parte de esta intervención, optamos por mantener las entradas que ya habíamos planteado en los anteriores edificios, incluyendo solo la nueva portada occidental de la que hemos hablado. Por este motivo mantenemos la ausencia de derrame que habíamos propuesto anteriormente para aquellas puertas.

Junto a la ampliación occidental hemos decidido incluir la torre románica, no porque necesariamente perteneciese a esta intervención, sino porque su construcción hubo de producirse en un momento muy cercano. Para esta conclusión cronológica hemos valorado el cuerpo de escaleras que se construye desplazado del campanario y que, al aprovechar el ángulo formado por la iglesia alta y el transepto, debe ser posterior a la construcción de aquel último (cerca de 1125). En el otro extremo hemos valorado cómo la torre condicionó la construcción del pórtico norte que, como después veremos, se data en el último cuarto del siglo XII y parece levantarse cuando ya existía el campanario. Estos dos datos, por tanto, nos ofrecen una horquilla que oscilaría entre 1125 y el último cuarto del siglo.

Sobre la estructura del campanario apenas conservamos la cimentación de su base ${ }^{76}$ y una somera descripción de Nebreda que decía": "Fue levantado un campanario, bastante elevado, a la manera de un castillo terminado con cilindros o bien columnas en los ángulos y otras decoraciones". Aunque realmente no conocemos su alzado, quizá pudo ser el modelo para un particular tipo de torre que se difundió en la Sierra de la Demanda a finales del siglo XII, las cuales fueron construidas por talleres con claros vínculos silenses y repetían una misma tipología que aún es reconocible en los campanarios de Vizcaínos de la Sierra, Jaramillo Quemado o Jaramillo de la Fuente ${ }^{78}$ (fig. 11).

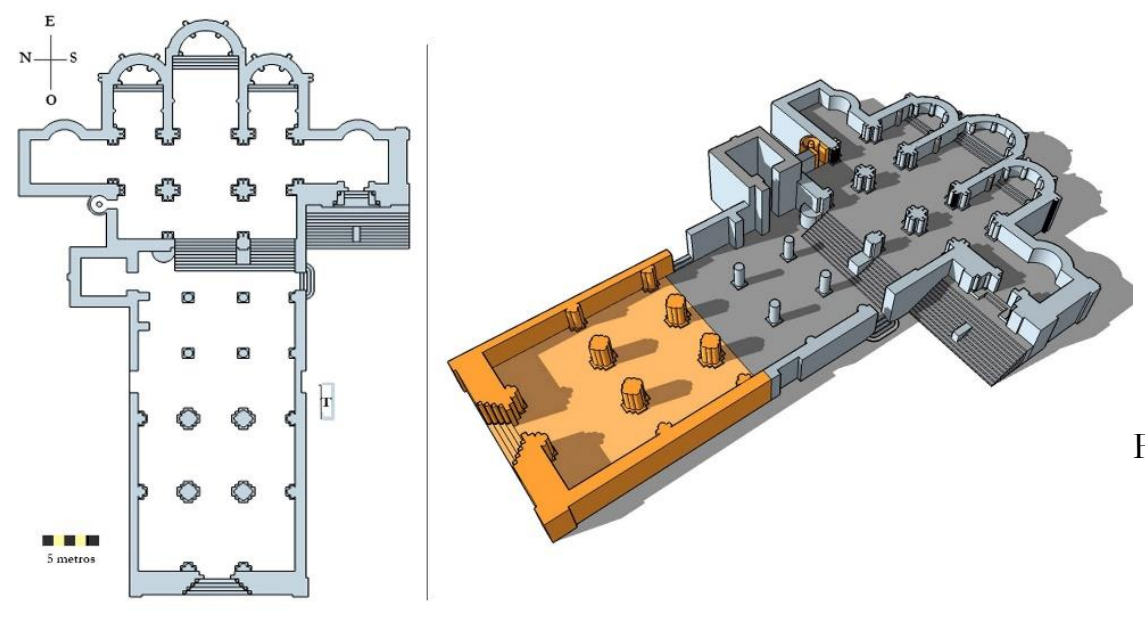

Fig. 11. Planta y sección de la ampliación occidental. Dibujos del autor.

${ }^{74}$ Bango pensaba que dicha forma fue representada por Sáiz tras conocer los restos arqueológicos durante las obras del museo (Bango, 1990: 340). Sin embargo, en una visita en 2017 el actual abad de Silos dudaba de aquel dato, ya que él estuvo presente en dichas obras y no tenía constancia de esos supuestos hallazgos. Además, la publicación del plano de Sáiz es anterior a las citadas obras del museo.

${ }^{75}$ Lozano planteó una interesante hipótesis sobre la posible existencia de arquerías ciegas en aquella fachada, sin embargo, carecemos de datos materiales que nos permitan trasladarlo a nuestros modelos gráficos: Lozano, 2009.

${ }^{76}$ Bango, 1990: 338.

${ }^{77}$ Palomero/Palomero, 2013a: 491.

${ }^{78}$ Resulta llamativo que algunos rasgos similares a los de esta tipología aparezcan en lugares tan distantes como la extremeña torre de Santa María de Trujillo: Rubio/Rubio, 2010: 28. Quizá, la existencia de un modelo similar en una obra de primer orden como Silos pudiera justificar la difusión de la tipología en lugares tan alejados. 


\section{Las últimas intervenciones románicas. La puerta norte y el pórtico}

La última intervención románica de la iglesia silense se centra en la construcción (o reforma, según lo que venimos exponiendo en este trabajo) de una portada en el lado norte y un pórtico rectangular tras ella, el cual actuaba como paso intermedio entre el núcleo de población y la iglesia, situándose, por los condicionantes geológicos, unos dos metros por debajo del nivel de la calle ${ }^{79}$. Esta intervención, gracias a los vestigios escultóricos asociados a los que después aludiremos, ha venido datándose de forma relativamente consensuada en una pequeña horquilla de tiempo que oscilaría entre 1170 y la última década del siglo XII ${ }^{80}$.

La existencia del pórtico románico era conocida por los historiadores gracias a la representación esquemática recogida en el plano de Echevarría y por las referencias documentales de los abades Jerónimo Nebreda y Baltasar Díaz. Las excavaciones del siglo $\mathrm{XX}$ sumaron a aquellas fuentes un importante número de restos arqueológicos, entre los que destacan: dos lienzos del lado norte del pórtico, la mitad de la portada exterior con cuatro escalones (fig. 12), parte del enlosado original, el tímpano de la portada interior y varias fotografías antiguas de esa puerta y su enlace con el muro de la iglesia. Con todos estos datos conservados se llegó a identificar el pórtico como una estancia rectangular de "90 pies de largo y 27 de ancho" 81 a la que únicamente se sumaba un pequeño pasillo oriental entre el muro de cierre y la torre, el cual fue reconocido por Bango gracias al recodo en el que finalizaba la construcción en ese extremo ${ }^{82}$.

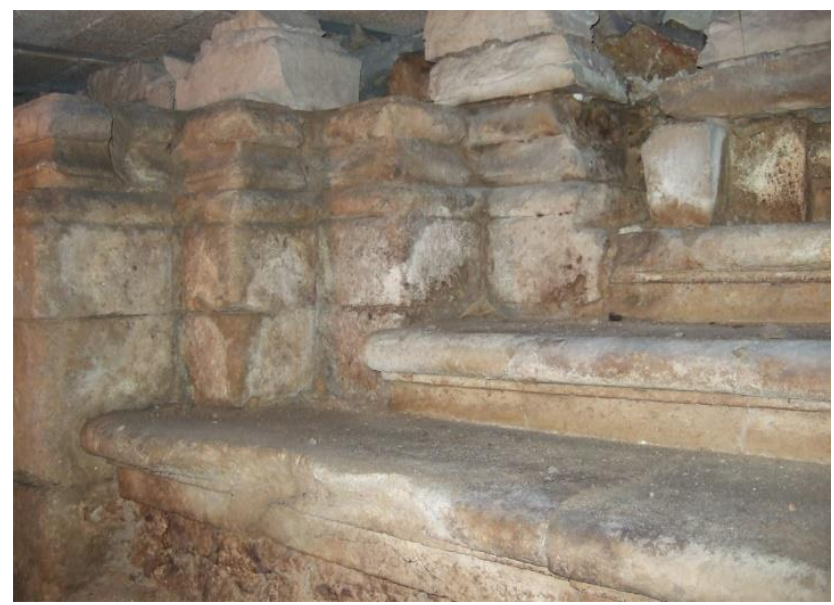

Fig. 12. Restos de la escalera del pórtico conservados bajo la actual iglesia. Fotografía del autor.

Del pórtico románico tenemos un conocimiento preciso de su planta gracias al plano de Echevarría y a los restos arqueológicos conservados, sin embargo, no conocemos prácticamente nada sobre la forma que pudo tener en alzado, pues sobre ello no han quedado representaciones gráficas ni referencias documentales. Esta situación ha dado lugar a dos modelos de interpretación sobre la forma en la que se cerraba su cara exterior, existiendo autores que defendían el uso de un muro macizo y otros que apostaban por una galería abierta de arcos semejante a la de otros pórticos castellanos ${ }^{83}$. Entre estas dos opciones es la segunda

\footnotetext{
${ }^{79}$ En el siglo XVI Nebreda ya hablaba de la "calle principal" situada en el frente de este pórtico: Ferotin, 1897: 360

${ }^{80}$ Boto, 2008: 46. Ocón, 2017: 318. Antolín, 2020.

${ }^{81}$ Esas medidas ( 27 x 8 en metros) fueron legadas por Baltasar Díaz y son similares a la escala de los planos modernos: Palomero/Palomero, 2013a: 492, nota 69.

${ }^{82}$ Bango, 1990: 340. La imagen de ese recodo en abierto en: Antolín, 2018: 100, figura 26.

${ }^{83}$ Una síntesis de este debate historiográfico en: Boto, 2003:139-140.
} 
la que ha alcanzado un mayor consenso durante las últimas décadas, pudiendo destacar los argumentos y justificaciones que esgrimieron autores como Bango, Frontón, Palacios o Boto $^{84}$, los cuales defendieron la existencia de aquella galería abierta con arcos que nosotros incluimos en nuestra propuesta y que ya tratamos con detalle un anterior trabajo de investigación ${ }^{85}$.

Sobre la forma y organización de aquellas posibles arquerías son muy pocos datos los que tenemos y, hasta donde sabemos, únicamente Palomero intentó trasladarlas gráficamente a un plano ${ }^{86}$. En esta cuestión es necesario valorar la posición descentrada del acceso que generaba dos pandas de longitudes desiguales, teniendo unos cinco metros la del lado oriental y casi catorce metros la del occidental, por lo que podemos intuir la existencia de una galería de arcos asimétrica similar a la de otros pórticos como los de Rebolledo de la Torre o Jaramillo de la Fuente. Con esas medidas conocidas, y si tomamos una proporción media de los arcos utilizados en las galerías castellanas ${ }^{87}$, pensamos que el lado oriental pudo tener entre dos y tres arcadas, mientras que el occidental tendría entre cinco y siete, siendo esos datos los que optaremos por trasladar a nuestros planos.

Sobre la forma que pudiera tener aquella arquería únicamente queremos destacar la existencia en el lapidario de Silos de un capitel de cuatro cestas, hoy fragmentado ${ }^{88}$, que se correspondería con un soporte cuádruple similar a los utilizados en las pandas del claustro y que nunca ha sido valorado como posible pieza de este pórtico (fig. 13). Aunque desconocemos la procedencia exacta de aquel capitel no tenemos constancia, a nuestro juicio, de otros lugares del monasterio que pudieran acoger un soporte cuádruple similar más allá de esta galería, a lo que deberíamos sumar la existencia de pórticos románicos vinculados a las corrientes silenses, como los sorianos de San Pedro de Caracena, San Martín de Berzosa o San Martín de Rejas de San Esteban, que a finales del siglo XII utilizaron este tipo de soporte en sus arquerías. Por este motivo, hemos decido incluir en la reconstrucción de la galería porticada una de esas columnas cuádruples que no resultaban inusuales en los pórticos tardorrománicos cercanos y que parece constatarse por el hallazgo de la pieza arqueológica.

Respecto a los accesos de la construcción contamos con tres puertas que debemos presentar estructuralmente: una que daba al exterior de la calle, otra que conectaba con la iglesia y una tercera situada en el pequeño pasillo del lado oriental. Respecto a la portada que
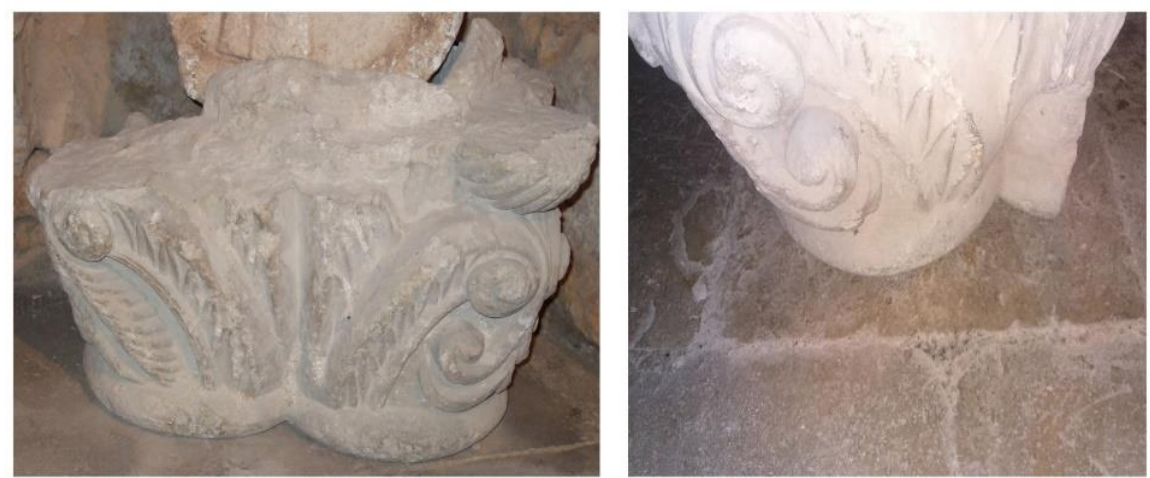

Fig. 13. Capitel cuádruple conservado en lapidario del monasterio. A la izquierda una vista frontal y a la derecha el arranque de las cestas posteriores fragmentadas.

${ }^{84}$ Bango, 1990: 340. Frontón, 1998. Palacios, 2000: 216. Boto, 2008: 46.

85 Antolín, 2018. Aunque este trabajo de formación contiene múltiples errores resulta de interés en algunas conclusiones estructurales y en el material gráfico que contiene.

${ }^{86}$ Palomero et alii, 1999: 327.

${ }^{87}$ Estas proporciones las justificamos en: Antolín, 2018: 313-314.

${ }^{88}$ Esta pieza, a primera vista, parece un capitel doble pero realmente es un bloque fragmentado que en su parte posterior conserva el arranque de otras dos cestas, en las cuales se observan restos del plumaje de algunas figuras que permiten relacionarlo con otras tallas tardorrománicas del monasterio. 
llevaba a la calle hemos conservado parte de su cara interna (fig. 12), lo que nos permite definirla como un acceso abocinado de cuatro recodos y cinco escalones que se proyectaba un metro hacia el interior del pórtico. Para representar la cara exterior de esta puerta, de la que no tenemos referencias estructurales, hemos decidido valorar la propuesta iconográfica de Frontón ${ }^{89}$, quien hablaba de una única arquivolta decorada que podría corresponder, en consecuencia, con una única pareja de columnas. En relación a la portada interior (entrada norte de la iglesia) debemos recordar que es la que tuvo el conocido tímpano que hoy se conserva en el museo silense ${ }^{90}$ y cuyos rasgos plásticos han permitido datarlo de forma fiable en el último cuarto del siglo XII ${ }^{11}$. Esta puerta se conoce bien a nivel estructural gracias a los restos arqueológicos de su machón oriental y a las fotografías antiguas que mostraban su estado en las excavaciones de $1964^{92}$, gracias a lo cual pudo definirse como una entrada abocinada con tres recodos y tres parejas de columnas que se proyectaban casi un metro hacia el interior del pórtico. La última entrada del edificio sería una pequeña puerta situada en el extremo oriental que podría ser similar a los sencillos ingresos que se abrieron en los lados cortos de otros pórticos castellanos (Jaramillo de la Fuente, por ejemplo), pero que aquí se encuentra precedida por un estrecho pasillo que queda entre el muro de cierre y la torre, el cual cuenta con un perfil inclinado de roca que originalmente pudo estar ocupado por algunos escalones que dotarían de funcionalidad a la puerta ${ }^{93}$. Por ese motivo, hemos decidido representar en este punto una escalera que ofrece un carácter funcional al espacio y da sentido a la existencia de la puerta en ese lado (fig. 14).
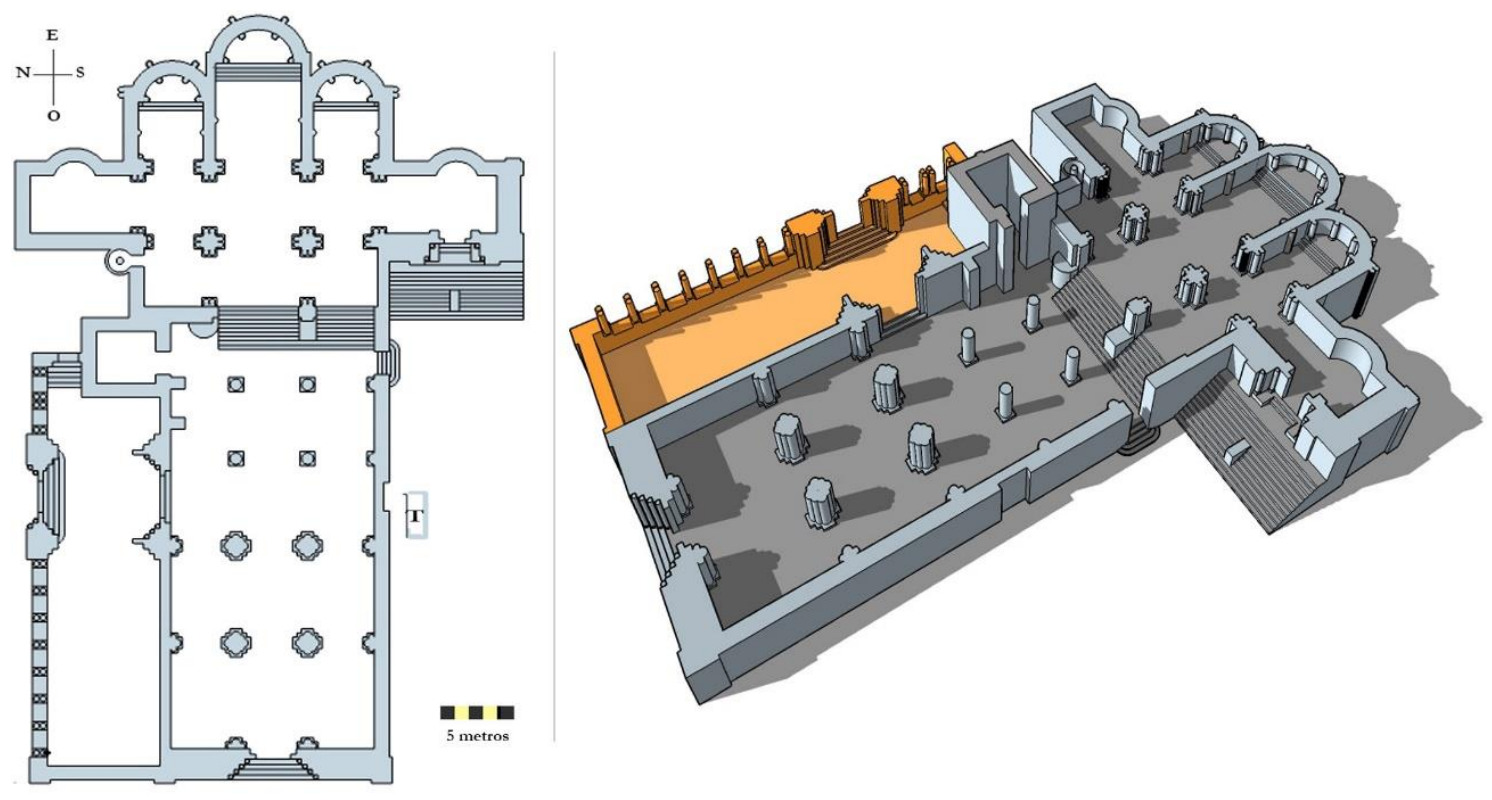

Fig. 14. Planta y sección del pórtico norte. Dibujos del autor.

\footnotetext{
${ }^{89}$ Frontón, 1996.

90 Sobre los estudios iconográficos del tímpano hallado en 1964, ver: Ocón, 2017. Valdez, 2020. Antolín, 2020.

${ }^{91}$ Boto, 2008: 46. Ocón, 2017: 318.

${ }^{92}$ Esas fotografías publicadas en abierto en: Antolín, 2018: 90-91, figuras 18-19.

${ }^{93}$ En este pequeño pasillo desaparece el enlosado del suelo y se conserva un sector de roca de perfil inclinado que lleva hasta la puerta. Desde el siglo XVI fue la conexión con un moderno relicario construido en su exterior: Palacios, 2000: 152-153.
} 


\section{Conclusión}

La importancia del monasterio de Silos en el románico hispano es el resultado de un conocimiento parcial de los edificios que se levantaron durante el periodo medieval, ya que solo las arquerías de su claustro, y apenas algunas dependencias, han sobrevivido completas hasta nuestros días ${ }^{94}$. Esa compleja trayectoria histórica, repleta de proyectos y propuestas de reforma arquitectónica, nos hace valorar la pérdida que supuso la renovación de su antigua iglesia, pues aquel edificio que desaparecía era un completo lienzo sobre la evolución artística del periodo medieval hispano, el cual nos hubiese dejado modelos arquitectónicos de diferentes etapas prerrománicas, de los proyectos tempranos del nuevo estilo románico y de la evolución de las formas artísticas hasta el siglo XIII.

La existencia de un templo con tantas fases constructivas era el resultado de continuos proyectos de ampliación que vinieron a solaparse unos a otros, los cuales hacen que su interpretación general resulte compleja desde múltiples aspectos: la forma de los edificios en planta, los elementos decorativos que se asocian a cada parte, la imagen de los alzados, las posibles repercusiones sobre el proceso constructivo del claustro o la datación de cada fase. Todos estos interrogantes son el resultado de un conocimiento parcial de las estructuras del antiguo edificio que da lugar, inevitablemente, a múltiples hipótesis sobre las etapas constructivas. En este trabajo hemos intentado presentar de forma breve las propuestas más destacadas que los historiadores han realizado durante los últimos años para elegir, de forma razonada, las que consideramos más adecuadas para los modelos gráficos que presentamos. Con ello, hemos intentado ofrecer un recorrido ordenado y coherente que sirva como referencia sobre la forma que pudo tener cada una de aquellas etapas constructivas.

El conjunto de representaciones gráficas, por tanto, no se trata de propuestas definitivas, sino que, realmente, son simples aproximaciones visuales que se acercan, con mayor o menor fortuna, a la imagen original que pudieron tener aquellos edificios. No sería descartable que cualquier autor, dados los múltiples interrogantes que aún existen sobre la desaparecida iglesia, pudiera introducir en estos modelos ciertas correcciones y variaciones que no serían, en muchos casos, menos válidas que las que hemos propuesto.

\footnotetext{
${ }^{94}$ Ver: Palacios, 2000.
} 


\section{Bibliografía}

Antolín Minaya, R.: Reconstrucción de la galería porticada románica de Santo Domingo de Silos (Burgos). Trabajo Fin de Máster, Uned. 2018, Recuperado de: http://espacio.uned.es/fez/view/bibliuned:master-GH-MTAIHAG-Rantolin

Antolín Minaya, R.: "La portada de la Navidad en la iglesia románica de Santo Domingo de Silos (Burgos): análisis de un programa iconográfico románico inspirado por la liturgia hispana”. En: Espacio, Tiempo y Forma. Serie VII, Historia del Arte, [8]. Madrid, 2020, pp. 343-368. DOI: https://doi.org/10.5944/etfvii.8.2020.26361

Bango Torviso, I.: "La iglesia antigua de Silos: del prerrománico al románico pleno". En: De la Serna González, Clemente (dir.): El románico en Silos: IX centenario de la consagración de la iglesia y el claustro, 1088-1988. Burgos: Abadía de Silos, 1990, pp. 317-376.

Boto Varela, G.: "Las galerías del milagro. Nuevas pesquisas sobre el proceso constructivo del claustro". En: Ibáñez Pérez, Alberto (dir.): Silos, Un milenio, Actas del congreso internacional sobre la abadía de Santo Domingo de Silos, Tomo IV, arte. Burgos: Universidad de Burgos, 2003, pp. 138-143.

Boto Varela, G.: "El santo de Silos: monumenta domésticos, hechuras hagiográficas y expansión devocional (s. XI-XIV)”. En: Español, Francesca / Fité, Francesc (eds.): Hagiografia peninsular en els segles medievals. Lleida: Universitat de Lleida, 2008, pp. 33-72.

Caballero Zoreda, L.: "Un conjunto constructivo altomedieval: Quintanilla de Las Viñas y las iglesias con cúpulas sobre pechinas de piedra toba de las provincias de Álava, La Rioja y Burgos”. 2015, En: Bermejo Tirado, Jesús (ed.), Arqueología de la arquitectura, [n¹2]. Madrid: Consejo Superior de Investigaciones científicas. DOI: http://dx.doi.org/10.3989/arq.arqt.2015.011

Ferotin, M.: Histoire de l'Abayye de Silos. París: Ernest Leroux. 1897, Recuperado de: https://bibliotecadigital.jcyl.es/i18n/consulta/registro.cmd?id=1868

Frontón Simón, I.: "El pórtico de la iglesia románica del monasterio de Silos: Datos para la reconstrucción iconográfica de su portada exterior". En: Boletín del Museo e Instituto Camón Aznar, [64]. Zaragoza, 1996, pp. 65-98.

Frontón Simón, I.: "Propaganda y autoafirmación de una institución monástica medieval: aproximación al programa iconográfico del pórtico del monasterio de Silos". En Boletín del Museo e Instituto Camón Aznar, [71]. Zaragoza, 1998, pp. 173-200.

Gaillard, G.: "L'Église et le cloitre de Silos: dates de construction et de la décoration". En: Bulletin Monumental, [91]. París, 1932, pp. 39-80. Recuperado de: https://www.persee.fr/doc/bulmo 0007-473x 1932 num 91 19933

García de la Borbolla, Á.: "Santo Domingo de Silos, el santo de la frontera: La imagen de la santidad a través de las fuentes hagiográficas castellano-leonesas del siglo XIII". En: Anuario de Estudios Medievales, volumen [31]. Pamplona, 2001, pp. 127-145. DOI: https://doi.org/10.3989/aem.2001.v31.i1.281

García González, J.J.: "Dominio del monasterio de Santo Domingo de Silos (954-1214)". En: De la Serna González, Clemente (dir.): El románico en Silos: IX centenario de la consagración de la iglesia y claustro. Burgos: Abadía de Silos, 1990, pp. 31-67.

Huidobro Serna, L.: "El arte visigótico y de la Reconquista: nuevos descubrimientos". En: Boletin de la Comisión Provincial de Monumentos Históricos y Artísticos de Burgos, Año 8, n²6. Burgos, 1929, pp. 361-368.

Klein, P.: "La puerta de las Vírgenes: su datación y su relación con el transepto y el claustro". En: De la Serna González, Clemente (dir.): El románico en Silos: IX centenario de la consagración de la iglesia y el claustro, 1088-1988. Burgos: Abadía de Silos, 1990, pp. 297-316.

Lozano López, E.: "Arquerías ciegas en fachadas del tardorrománico castellano: una revisión historiográfica”. En: Anales de Historia del Arte, [1]. Madrid, 2009, pp. 281-294. Recuperado de: https://revistas.ucm.es/index.php/ANHA/article/view/38398 
Lozano López, E.: "Maestros castellanos del entorno del segundo taller silense: repertorios figurativos y soluciones estilísticas". En: Neue Forschungen zur Bauskulptur in Frankreich und Spanien. Berlín. 2010.

Merino de Cáceres, J. M. / Reynolds Álvarez, M.: "Metrología y composición del monasterio de Silos". En: Rabasa Díaz, Enrique (aut.): Actas del XII Congreso Internacional de Expresión Gráfica Arquitectónica. Madrid: Universidad Politécnica, 2008, pp. 559-568.

Moralejo Álvarez, S.: “El claustro de Silos y el arte de los caminos de peregrinación”. En: De la Serna González, Clemente (dir.): El románico en Silos: IX centenario de la consagración de la iglesia y el claustro, 1088-1988. Burgos: Abadía de Silos, 1990, pp. 203-215.

Moreno Martín, F.: "Espacios y arquitectura de los monasterios dúplices en la Alta Edad Media: en busca de un modelo predictivo". En: García de Cortázar, José Ángel / Teja, Ramón (coord.): El monasterio medieval como célula social y espacio de convivencia. Aguilar de Campoó; Fundación Santa María la Real, 2018, pp.59-66. Recuperado de: https://www.academia.edu/35866398/Espacio y arquitectura de los monasterios d $\% \mathrm{C} 3 \%$ BAplices en la alta Edad Media en busca de un modelo predictivo

Ocón Alonso, D.: "La Presentación en el Templo de la puerta norte de la iglesia del monasterio de Santo Domingo de Silos y su relación con algunos paradigmas artísticos del mundo mediterráneo". En: Poza Yagüe, Marta / Olivares Martínez, Diana (coord.): Alfonso VIII y Leonor de Inglaterra: confluencias artísticas en el entorno de 1200. Madrid: Universidad Complutense, 2017, pp.315-356.

Orduña Cuevas, M.: "Una aproximación a la topografía claustral del monasterio de Santo Domingo de Silos (s. XI-XII)". En: Revista de Historia Autónoma, [6]. Madrid, 2015, pp. 11 27.

Palacios Palomar, C.: Patrimonio artístico y actividad arquitectónica del monasterio de Silos 1512-1835 (Tesis doctoral). Universidad de La Laguna. 2000. Recuperado de: https://riull.ull.es/xmlui/handle/915/10011

Palomero Aragón, F. / Ilardia Gálligo, M. / Reyes Téllez, F. / Maté Sadornil, L.: Silos: Un recorrido por su proceso constructivo. Burgos: Caja Burgos. 1999

Palomero Aragón, F. / Palomero Ilardia, I.: "San Sebastián de Silos: la iglesia dedicada o consagrada en torno a 1088 a través de la documentación y los restos arqueológicos". En: Imago temporis. Medium Aevum, [7]. Lleida, 2013a, pp. 476-498. Recuperado de: https://raco.cat/index.php/ImagoTemporis/article/view/292992

Palomero Aragón, F. / Palomero Ilardia, I.: "San Sebatián de Silos: the Church Dedicated or Consecrated around 1088 through the Documentation and Archaeological Remains". En: Imago temporis. Medium Aevum, [7]. Lleida, 2013b, pp. 139-174. Recuperado de: https://raco.cat/index.php/ImagoTemporis/article/view/292959

Pascual Blanco, S. / Escribano Martínez, F.: Nuestra Señora del Cerro (Cueva de Juarros, Burgos): una ermita prerrománica al margen de estereotipos". En: Vestir la arquitectura: XXII Congreso Nacional de Historia del Arte, Vol. 2. Burgos, 2019, pp. 14351440.

Pérez Urbel, J.: El claustro de Silos. Burgos: Imprenta Aldecoa. 1955.

Rubio Andrada, M. / Rubio Muñoz, F. J.: La torre románica de Santa Maria, Trujillo (Cáceres). Estudio arqueológico. 2010. Recuperado de: https://chdetrujillo.com/la-torre-romanica-desanta-maria-trujillo-caceres-estudio-arqueologico/?pdf $=3228$

Senra G. y Galán, J. L.: “Santo Domingo de Silos”. En: García Guinea, Miguel Ángel / Pérez González, José María (dir.): Enciclopedia del románico. Burgos, Vol. I. Aguilar de Campoo: Fundación Santa María la Real, 2002, pp.2539-2571. https://www.romanicodigital.com/sites/default/files/pdfs/files/burgos SANTO DO MINGO DE SILOS.pdf 
Senra G. y Galán, J. L.: "Santo Domingo de Silos: New Interpretive Suggestions for the Medieval Church (1041-1143)". En: Martin, Therese / Harris, Julie (eds.): Church, State, Vellum, and Stone: Essays on Medieval Spain in Honor of John Williams. Leiden/Boston, 2005, pp. 329-372.

Senra G. y Galán, J. L.: "El monasterio de Santo Domingo de Silos y la secuencia temporal de una singular arquitectura ornamentada". En: Huerta Huerta, Pedro Luis (ed.): Siete maravillas del románico español. Aguilar de Campoo: Fundación Santa María la Real, 2009, pp.193-225.

Valcárcel, V.: La "Vita Dominici Silensis" de Grimaldo. Estudio, crítica y traducción. Logroño: Instituto de estudios riojanos Berceo. 1982.

Váldez del Álamo, E.: Palace of the Mind. The Cloister of Silos and Spanish Sculpture of the Twelfth Century. Turnhout: Brepols. 2012.

Valdez del Álamo, E.: "With Faithful Mind: the pilgrimage to Santo Domingo de Silos". En: Plant, Richard / McNeill, John (eds.): Romanesque saints, shrines and pilgrimage. Abingdon: Routledge, pp.203-213. Recuperado de: https://www.academia.edu/43596574/With Faithful Mind the Pilgrimage to Santo Domingo de Silos 2020.

Vivancos Gómez, M. / Del Río, Pablo Arturo / Rivalta, Víctor Manuel: "Hallazgo de una tumba de los siglos X-XI en el monasterio de Silos". En: Boletín del Museo Arqueológico Nacional, [Tomo 21-23], [n¹-3]. Madrid, 2003-2005, pp. 39-46.

VV.AA.: Silos y su época. Madrid: Ministerio de Educación y Ciencia. 1973. 